قياس وتحليل أثر الانفاق العام على متغيرات المربع السحري لـ (kaldor) في المملكة العربية السعودية

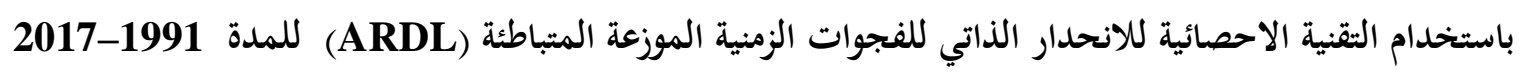

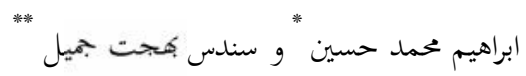

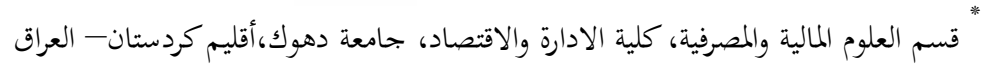

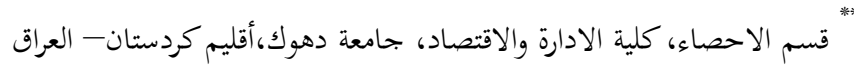

$$
\begin{aligned}
& \text { (تاريخ استلام البحث: } 10 \text { شباط، 2019، تاريخ القبول بالنشر: } 28 \text { آذار، 2019 }
\end{aligned}
$$

الخلاصة

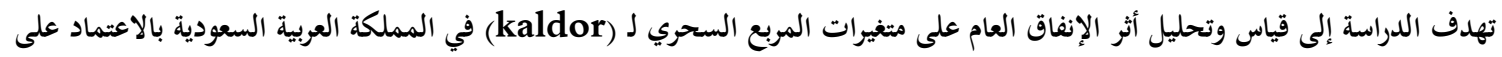

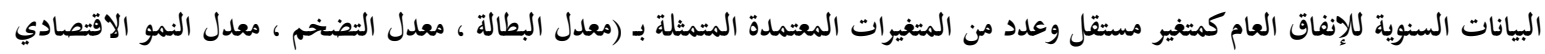

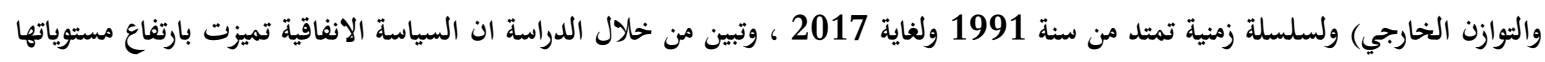

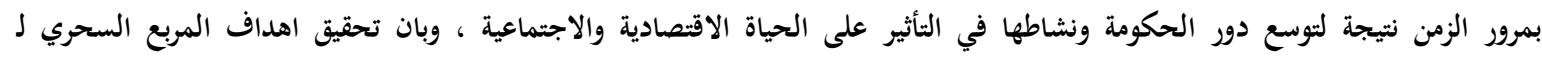

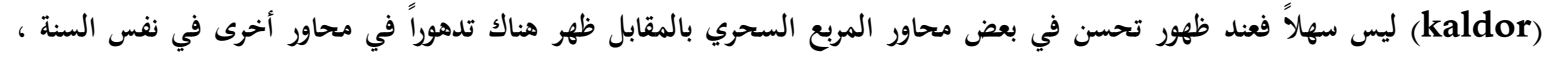

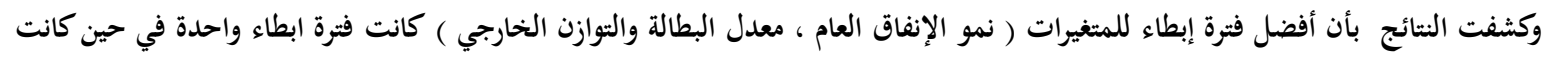

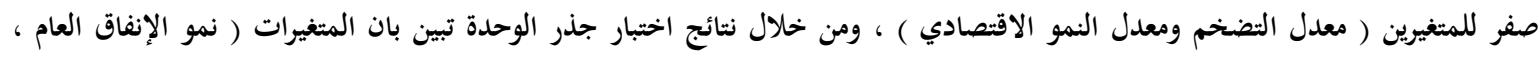

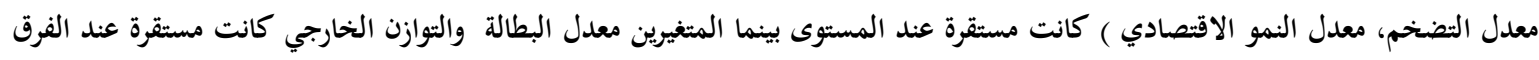

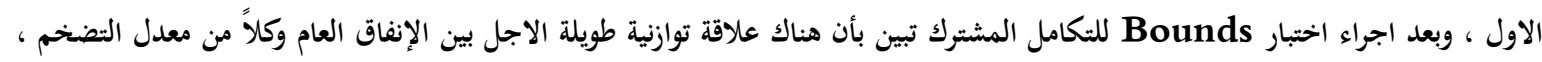

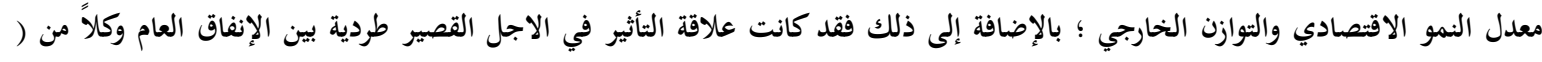

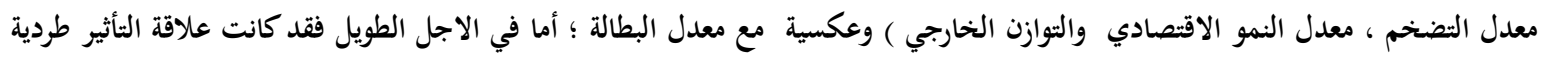

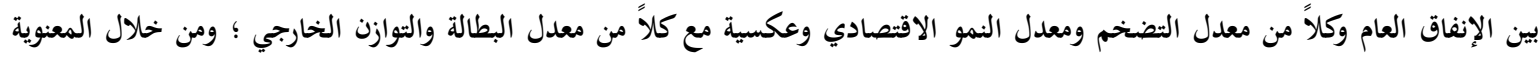

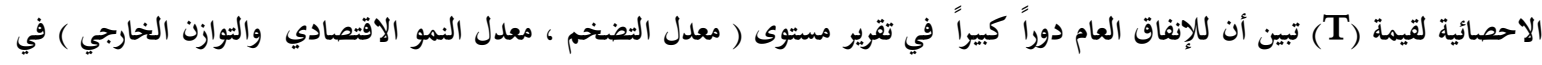

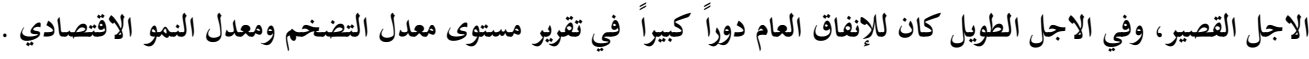
الكلمات المغتاحية : الانفاق العام ، المربع السحري لـ (kaldor) ، معدل البطالة ، معدل التضخم ، معدل النمو الاقتصادي ، التوازن الخارجي .

متغيرات مهمة متمثلة بمعدل التضخم والبطالة والنمو

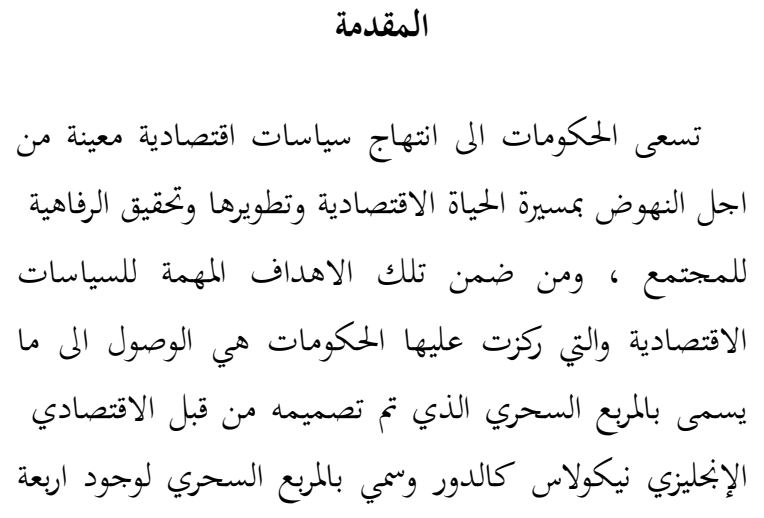

الاقتصادي والتوازن الخارجي ؛ وهذه المتغيرات تمثل مؤشرات

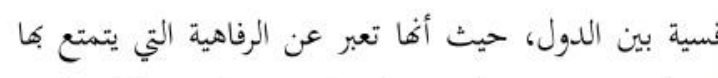

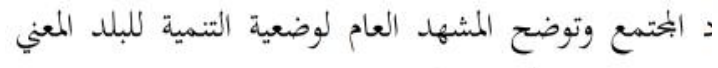

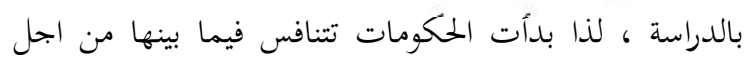

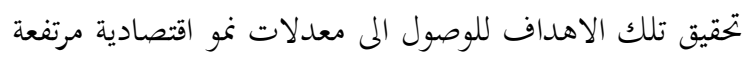

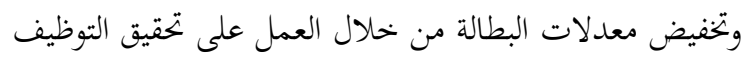


يمكن معالجة تلك المشاكل او التخفيف من حدقّا قدر الامكان

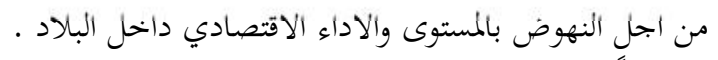
ثانيا : فرضيات الدراسة تستند الدراسة على الفرضيات الآتية :

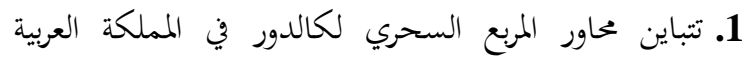

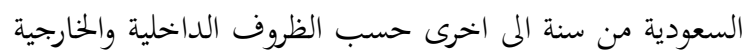
المخيطة بالبلد . السعودية من سنة 2. توجد علاقة تأثيرية عكسية ذات دلالة احصائية بين الانفاق العام ومعدل البطالة .

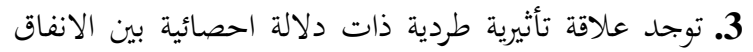

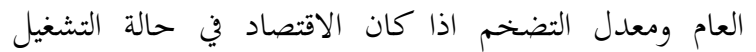

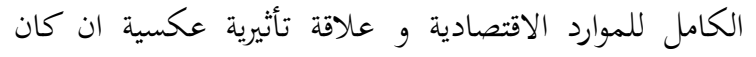
الاقتصاد دون التشغيل الكامل للموارد الاقتصادية .

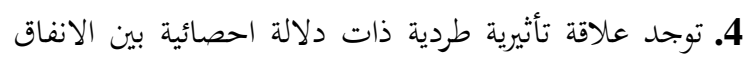

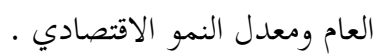
5. توجد علاقة تأثيرية طردية ذات دلالة الحادي الحصائية بين الانفاق

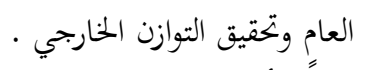

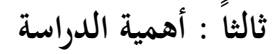

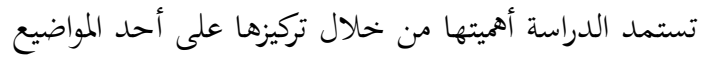

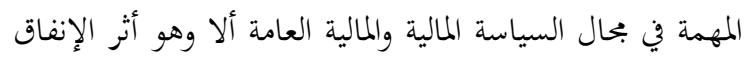

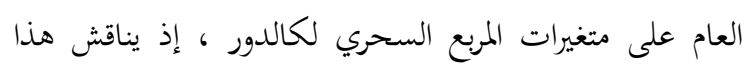

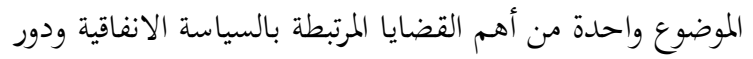

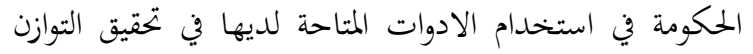

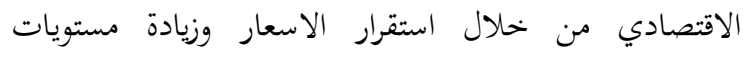

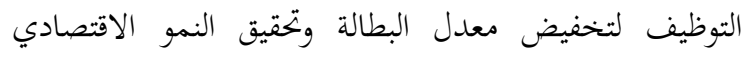

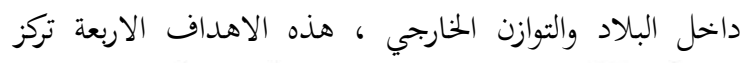

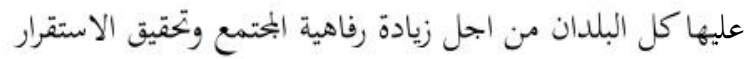

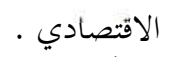

رابعاً : أهداف الدراسة

$$
\text { تسعى الدراسة إلى تحقيق الأهداف الآتية : }
$$

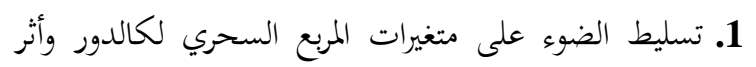

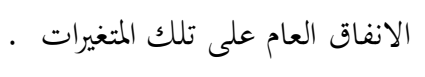

2. بيان ابتحهات متغيرات المربع السحري لكالدور في المملكة

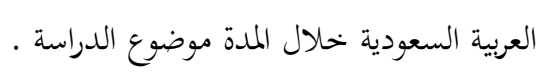

الكامل وكبح جماح التضخم للرفع من القدرة الشرائية للمواطنين وتحقيق التوازن في ميزان المدفوعات . وعلى الرغم من ان تحقيق أهداف المربع السحري لكالدور

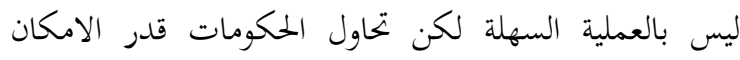
تحقيقها والوصول المى اقصى حد ممكن من الاداء الذي يحسن

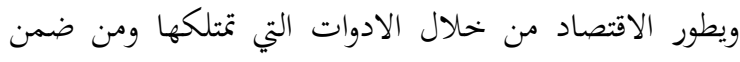

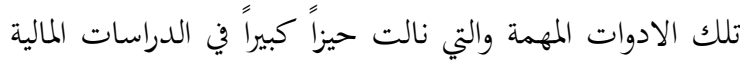
ما يعرف بالسياسة الانفاقية والتي تعتبر أداة رئيسية من أدوات

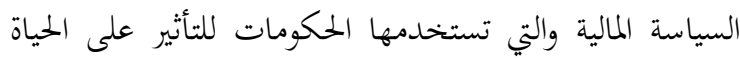

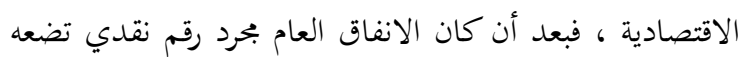

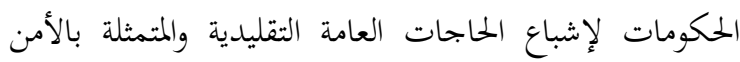
والدفاع والقضاء أصبحت اليوم وسيلة وأداة بيد الحكومة

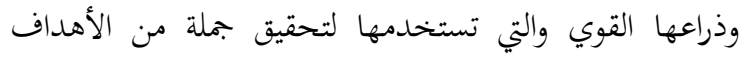
والمتمثلة بتحقيق التوازن الاجتماعي والاقتصادي والسياسي

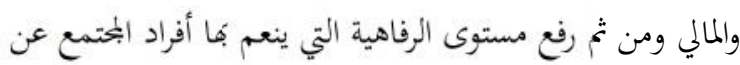

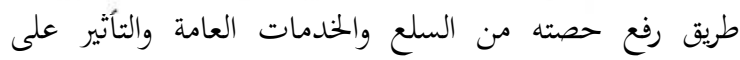
مؤشرات الاقتصاد الكلي ولتحقيق هذا الهدف ترتب على عاتق

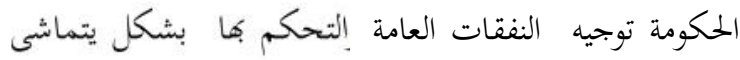
مع الظروف والتطورات السائدة في الاقتصاد لذا فهو يعكس

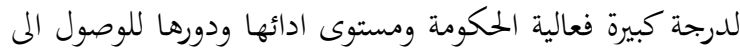

$$
\text { أولاً : مشكلة المربع السحري لكالدور . مدراسة }
$$

تعاني اغلب البلدان من مشاكل اقتصادية جمة من ابرزها

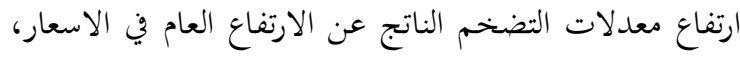

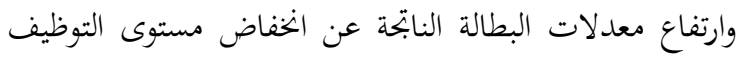

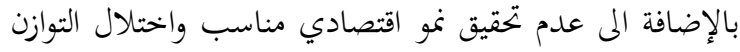

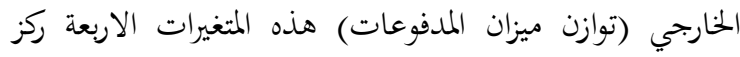

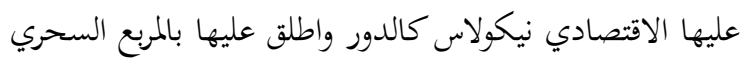

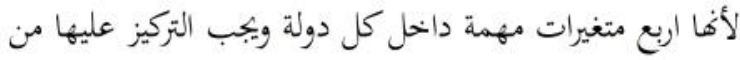

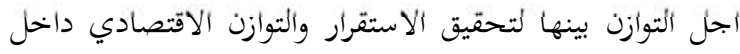

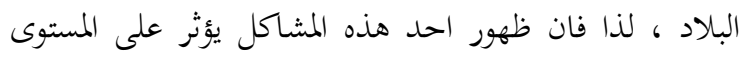

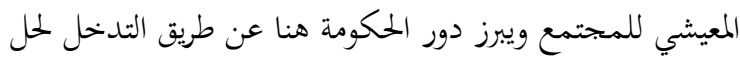
تلك المشاكل الاقتصادية وباستخدام ادوات السياسة المالية 
أهداف تعرف بالمربع السحري لكالدور · (مسعودي ،2017:

تم تصميم المربع السحري من طرف الاقتصادي الإنحليزي

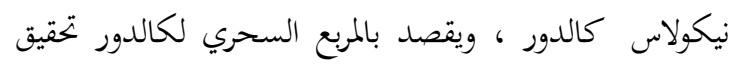

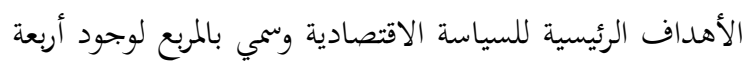

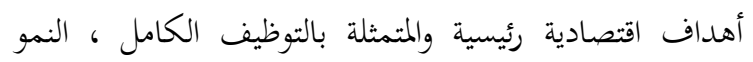

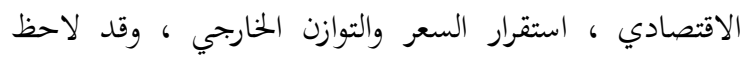

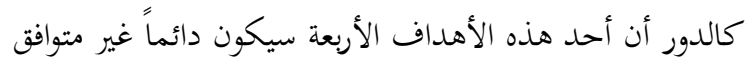
مع الاهداف الاخرى ، فلا يمكن تحقيق العمالة الكاملة والنمو

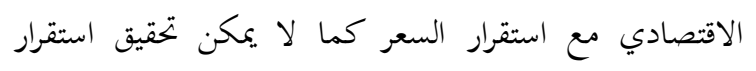

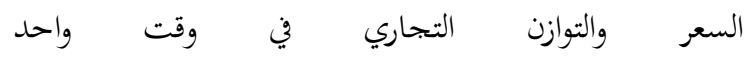

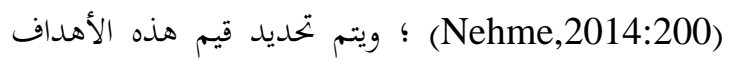
بنقاط على معلم متعامد ومتجانس وربط هذه النقاط ببعضها

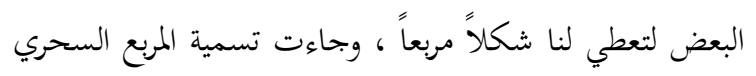

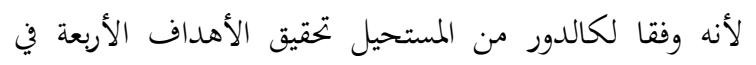
نفس الوقت. (habil \& et al.,2017:38) والمربع السحري كما هو موضح في الشكل (1) هو عبارة عن رسم تخطيطي رباعي القياس يحتوي على الأهداف الأربعة للسياسة الاقتصادية والمتمثلة بالآتي :

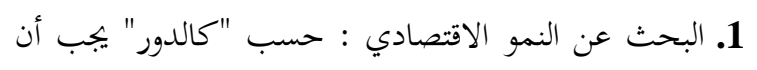

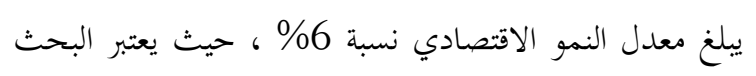
عن النمو الاقتصادي الهدف الأكثر عمومية، والمتمثل في زيادة حجم الدخل الوطني عبر الزمن، أي ما يلاحظ من خلال هذا

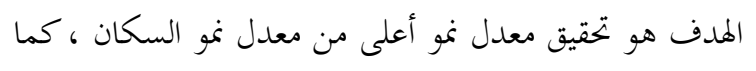

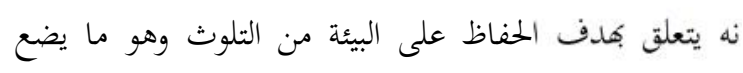
أمام صانعي السياسة الاقتصادية في كيفية تحقيق معدل نمو

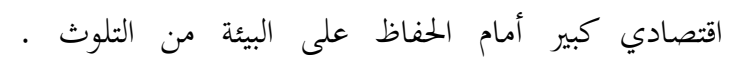

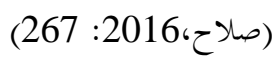

2. البحث عن التشغيل الكامل : حسب "كاح، "حالدور" يجب أن

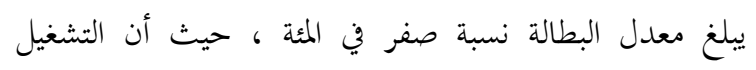
الكامل يعني زيادة حجم العمالة وتحقيق أقصى مستوى من التوظيف والعمل على تحقيق أدنى حجم من البطالة كما أن
3. تحليل علاقة التكامل المشترك بين الانفاق العام ومتغيرات

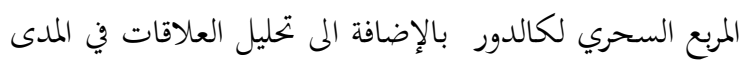
القصير والطويل بين تلك المتغيرات في المملكة العربية السعودية خلال المدة موضوع الدراسة . خامساً : متغيرات الدراسة والمدة الزمنية تم تحليل بيانات سلسلة زمنية سنوية لمدة 27 سنة وللفترة ما

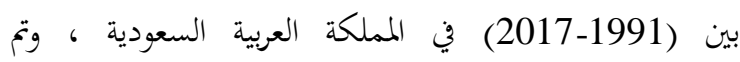

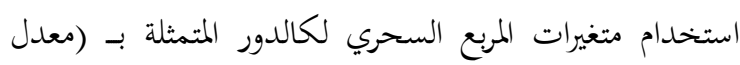

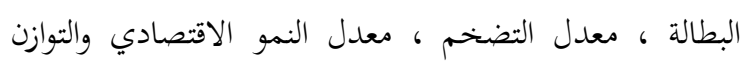

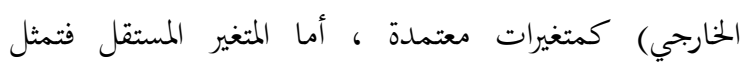
بالإنفاق العام وتم التعبير عن جميع المتغيرات بنسب مئوية . سادساً : الاساليب المستخدمة في تحليل الدراسة تم استخدام الاسلوب الوصفي التحليلي لتحليل ابتاهات

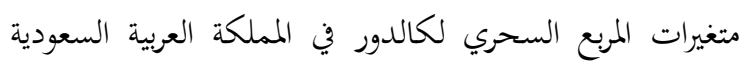
بالإضافة الى الاسلوب الاحصائي القياسي الكمي لتحليل

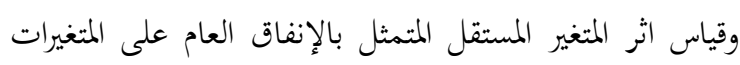

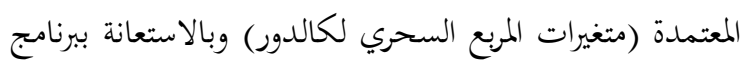
تم اتباع طرق واختبارات قياسية حديثة للإجراء (Eviews) التحليل كاختبار الاستقرارية والتكامل المشترك وتحليل العلاقات

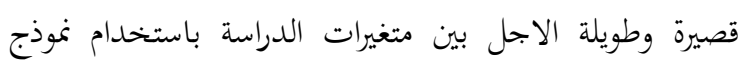

. (ARDL)

\section{المبحث الاول}

\section{الاطار النظري للمربع السحري لكالدور}

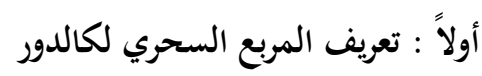

تؤكد معظم الدراسات الاقتصادية على أن هدف أي الع العريف

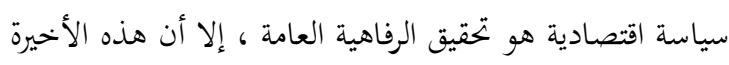

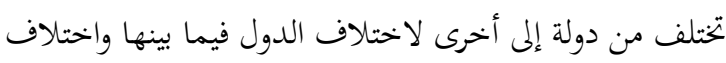

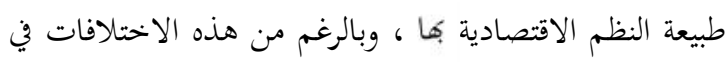

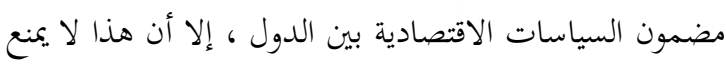
من وجود أهداف مشتركة بين السياسات الاقتصادية الكلية

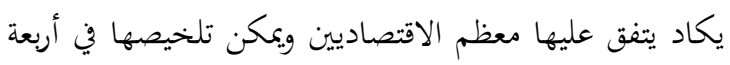


استقرار الأسعار والتوظيف الكامل هي إحدى الحالات التي

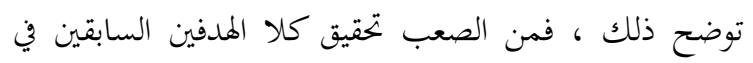

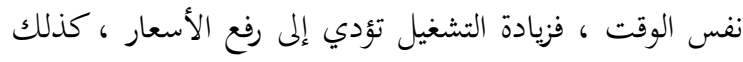
هناك صعوبة بالنسبة لتحقيق التشغيل التام وتوازن ميزان المدفوعات ، فزيادة حجم الصادرات تقتضي خفض مستوى

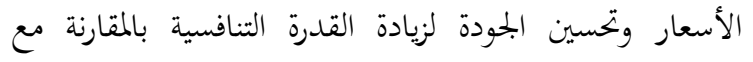

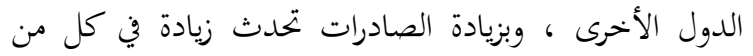

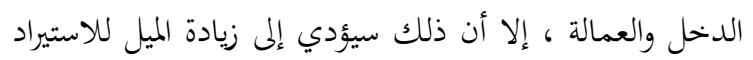

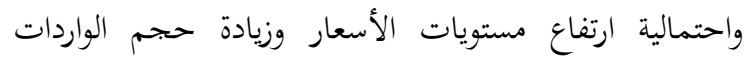

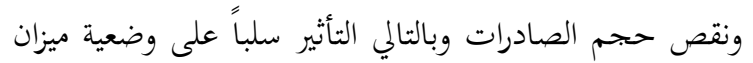

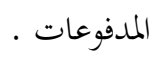

أما العلاقة بين النمو الاقتصادي واستقرار الأسعار فهي

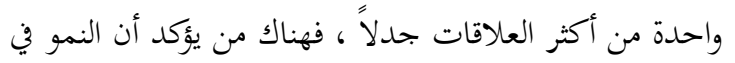
المدى الطويل لن يتحقق ما لم يكن هناك استقرار في مستويات

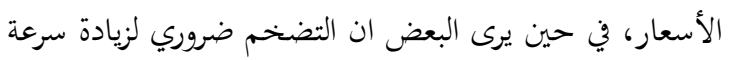

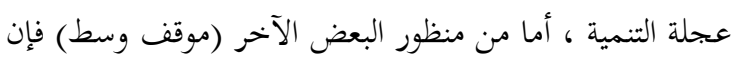
التضخم لا يساعد على تحقيق معدل أسرع للنمو إلا أنه يكون

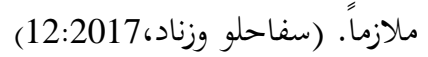

مفهوم التشغيل الكامل يشير إلى الاستخدام الكامل لكل عوامل الإنتاج والتي يعد عنصر العمل من أهمها . 3. التحكم في التضخم : الذي يعبر عنه بالارتفاع المستمر

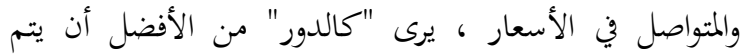

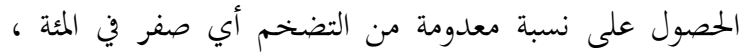
حيث أن عدم التحكم فيه يؤدي إلى تشويه المؤشرات

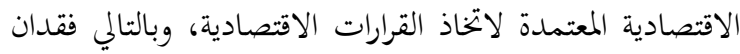
الثقة من طرف الأعوان الاقتصاديين في السياسة الاقتصادية . 4. البحث عن التوازن الخارجي : والذي يتمثل في توازن ميزان المدفوعات إذ يعكس وضع ميزان المدفوعات موقع الاقتصاد القومي تجاه باقي الاقتصادات ، حيث يؤدي الاختلال في ميزان

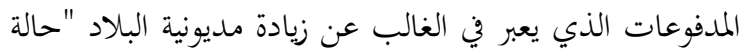

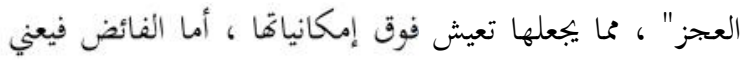
العيش في مستوى معيشي أقل من إمكانيات هذه الدولة ،

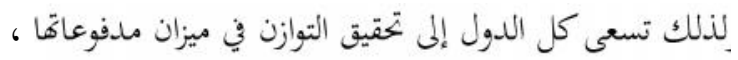
ويعبر عن التوازن الخارجي بنسبة رصيد ميزان المدفوعات إلى

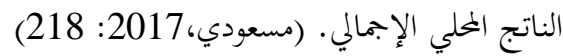

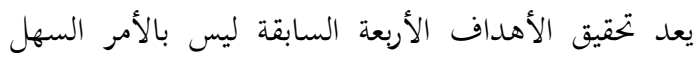
وذلك لتعارض هذه الأهداف مع بعضها البعض ، فالعلاقة بين

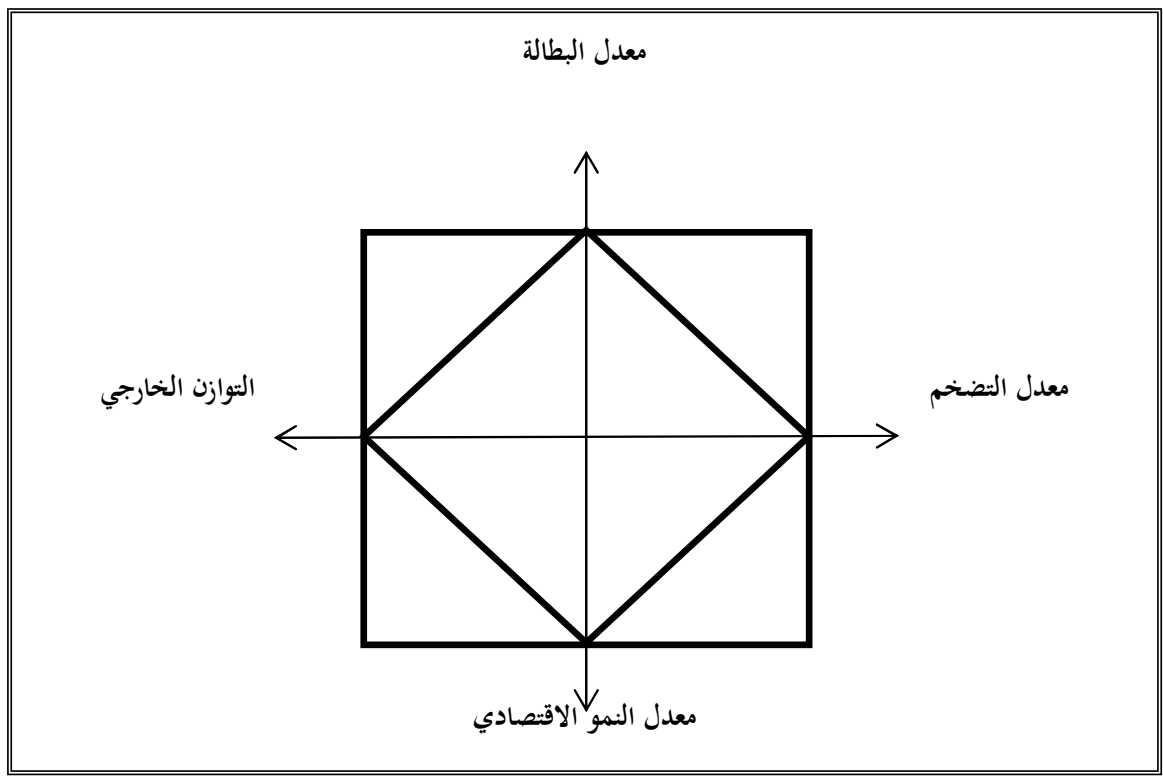

Source : Neantro, Saavedra-Rivanoa \& Joanilio Rodolpho Teixeiraba , 2017 , Magic hypercube and index of welfare and sustainability, Economia, Vol. 18, page 90 . 
سواء كان ذلك ضمن السياسات الظرفية أو الهيكلية. (دشوشة

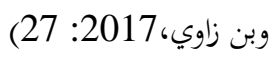
نظرياً يعتبر الإنفاق العام المحرك الأساسي الذي يمكن من

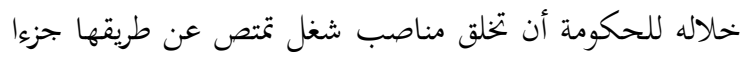

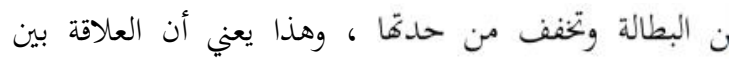

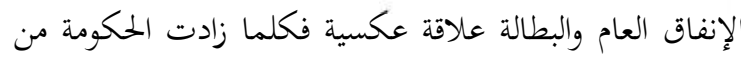

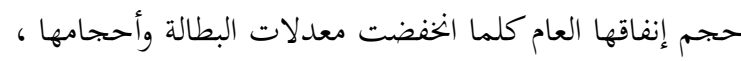
كما أن السياسة المالية بشكل عام وبمختلف آلياتما بما فيها سياسة الإنفاق العام تعتبر من أبخح السبل والأدوات التي تعالج حالات الركود الاقتصادي أو الفجوات الانكماشية ، لأنها

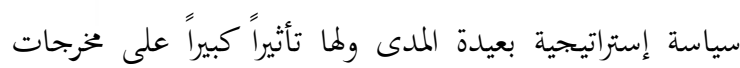

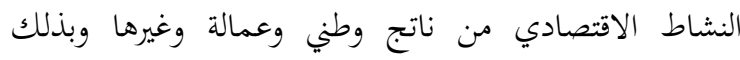
فالمشاريع الحكومية تعمل على توليد مناصب شغل لسنوات متتالية . (مقراني،2015: 27)

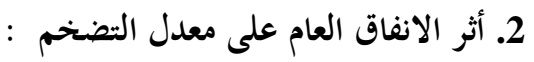
تعتبر مشكلة التضخم اليوم من المشاكل الاقتصادية المعاصرة

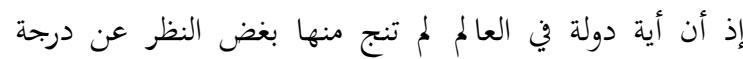
تقدمها أو تطورها و ن درجة الرفاهية التي ينعم بها مواطنيها و و الفة الفائض المالي التي يتمتع بها ميزان مدفوعاتما (الأعظمي،78:2000) ؛ ويعرف التضخم بأنه الارتفاع في بئن المستوى العام للأسعار بشكل مستمر ومتواصل ، ويتحقق التضخم عند حصول الارتفاع في المستوى العام للأسعار لكل

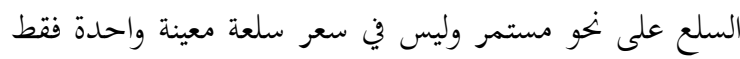

(Delong,2002:327) أن سبب التضخم هو ارتفاع الطلب الكلي أي أن هناك قوة شرائية زائدة، ففي هذه الحالة تتدخل الدولة باستخدام

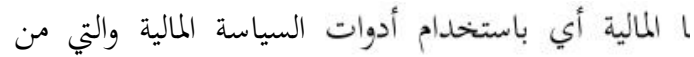
ضمنها السياسة الإنفاقية حيث تقوم الحكومة بالعمل على

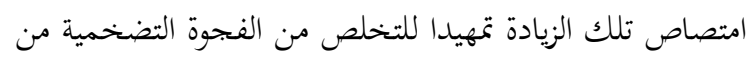
خلال خفض الإنفاق الحكومي الذي يمثل أحد المكونات

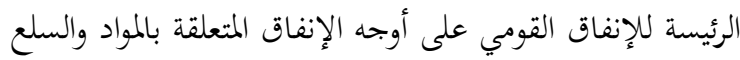

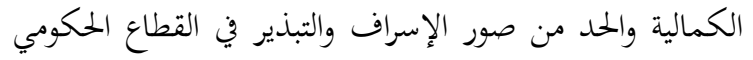

ثانياً: أثر الانفاق العام على متغيرات المربع السحري

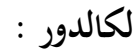
يمكن توضيح أثر وطبيعة العلاقة بين الانفاق العام و متغيرات المربع السحري لكالدور بالنقاط الآتية : 1. أثر الانفاق العام على معدل البطالة : ان مشكلة البطالة العالية هي واحدة من أكثر القضايا

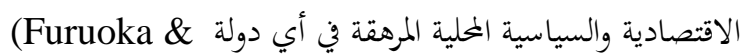
( Munir,2014:36) ، فالبلدان التي تعاني من معدلات البطالة

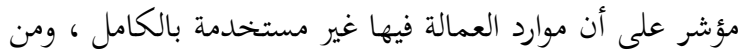

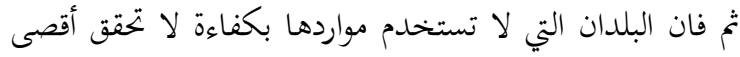

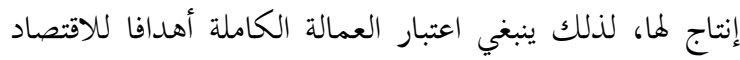

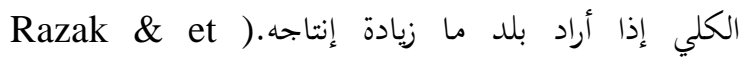

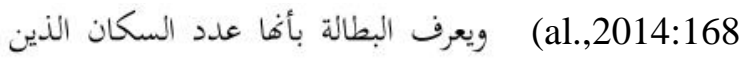

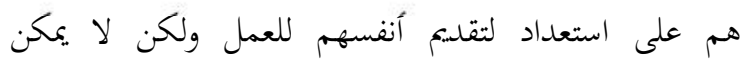
توظيفهم بسبب عدم وجود وظائف شاغرة لمم، وقد حددت منظمة العمل الدولية قوة العمل في أي دولة بتلك التي تنتمي إلى الفئة العمرية من 15 إلى 65 سنة . (Jajere,2016:182) ويمكن للدولة تفادي حدوث ظاهرة البطالة من خلال سياسة الإنفاق الحكومي ، إذ أن وجود بطالة متزايدة معناه

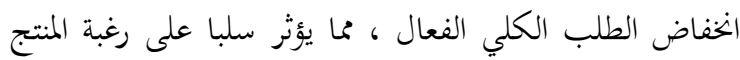

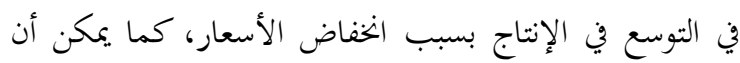
يؤدي إلى إيقاف بعض خطط الإنتاج مما يدخل الاقتصاد في حلقة مفرغة من الخفاض الطلب الكلي وارتفاع مستوى البطالة، وهنا تكون اتباع سياسة توسعية في بحال الانفاق العام كفيلة

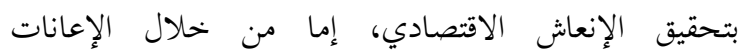
الاقتصادية للمنتجين التي تساهم في زيادة تشغيل الموارد المتاحة أو من خلال قيام الدولة بإنشاء مدن جديدة ومدها بجميع الخدمات الأساسية ، الامر الذي يسمح بخلق فرص جديدة بلدية

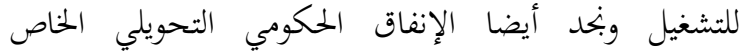
بالمعاشات والتأمين الذي من شأنه زيادة اطمئنان الأفراد على الإنى التهيل مستقبلهم له أثر كبير على زيادة إنتاجهم ، وتحتل سياسة الإنفاق الحكومي موقعا هاما ضمن سياسات مكافحة البطالة 


\section{3. أثر الانفاق العام على معدل النمو الاقتصادي :} يعتبر النمو الاقتصادي المرآة العاكسة للنشاط الاقتصادي ودرجة تطوره وكان محل اهتمام العديد من الاقتصاديين أولهم روبرت مالتوس سنة 1798 في كتابه ( مبدأ الامة ) وتبعه بعد الدماند ذلك العديد من الباحثين الاقتصاديين بشكل يعكس الاهمية

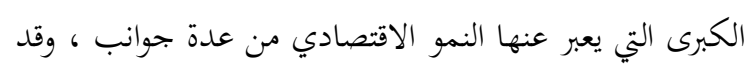

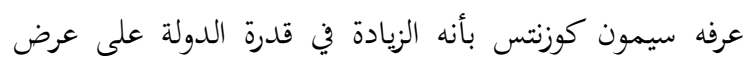

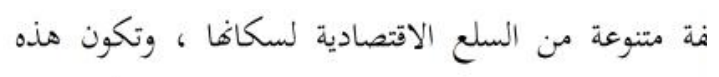

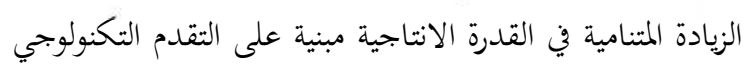

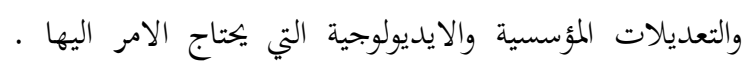
(تودارو،175:2006) ؛ وعرفه شبيرو بأنه الزيادة في الإنتاج

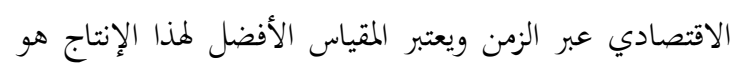

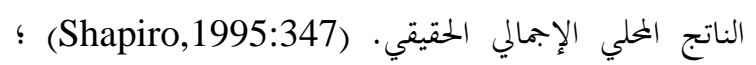
كما عرفه ساميلسون ونوردوس بأنه العامل الأهم في تحديد بحاحات الدول على المدى الطويل. \&amuelson \&) Nordhaus , 2001:265) تعد مسألة تأثير الإنفاق الحكومي على النمو الاقتصادي

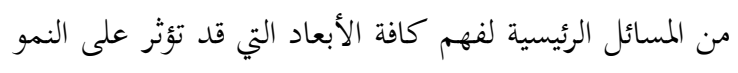
الاقتصادي ، وذلك بسبب الدور الرئيسي الذي يلعبه الإنفاق

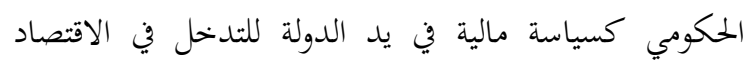

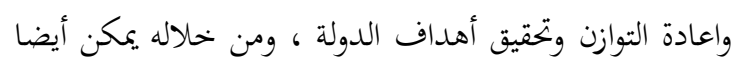

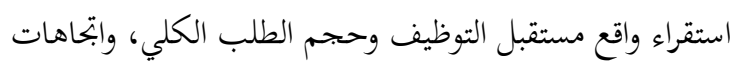

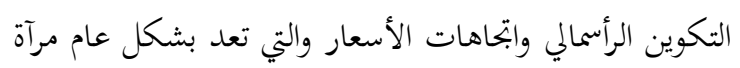
للنمو الاقتصادي. كما يعد الإنفاق الحكومي محركاً للنمو الاقتصادي من

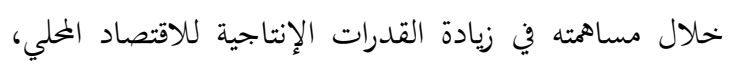
وذلك إذا ما وجه بصورة صحيحة نحو قطاعات الاقتصاد

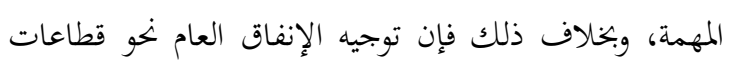

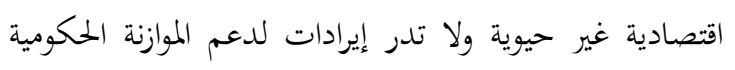

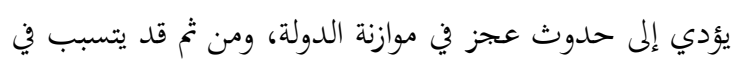

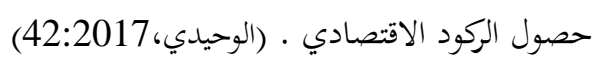

مع عدم الإخلال بأي شكل من أشكال الإنفاق التي تحدف

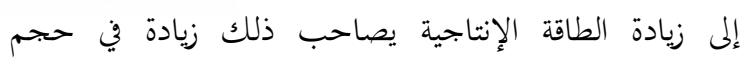
الضرائب. أما في حالة الانكماش وعندما تتحدد المشكلة في قصور الطلب الكلي أي أن هناك ثمة حاجة لخلق قوة شرائية جديدة

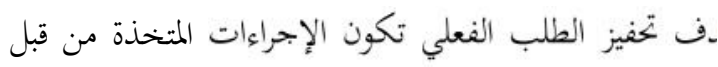

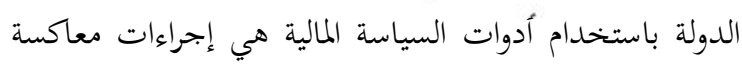
لحالة التضخم حيث تقوم الدولة بزيادة الإنفاق الحكومي

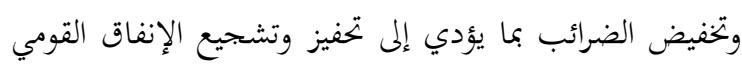
حتى يقترب مستواه من مستوى الإنتاج القومي فتختفي تدريجيا

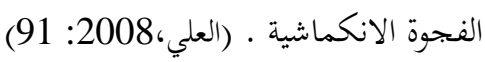

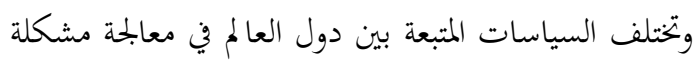
التضخم حسب الوضع السائد في اقتصادها ، فاذا كان الاقتصاد في حالة التشغيل الكامل للموارد الاقتصادية أو في مرحلة قريبة من ذلك فإن العرض يكون عديم المرونة وأن أي الئي

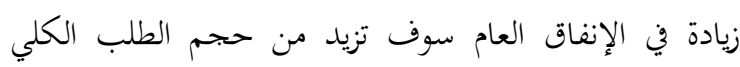

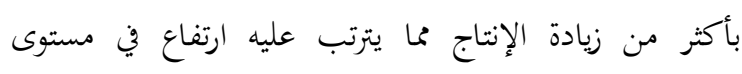
الأسعار. أما إذا كان الاقتصاد دون التشغيل الكامل للموارد الاقتصادية وكان الجهاز الإنتاجي عالي المرونة ، أي هناك الدان

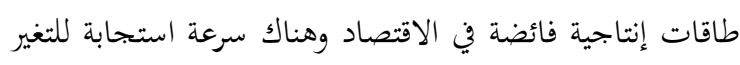

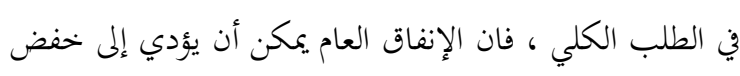

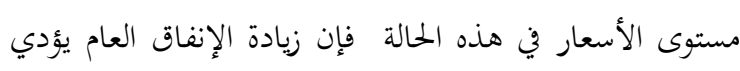
إلى زيادة كبيرة في الإنتاج، وإذا كانت هذه الزيادة في الإنتاج

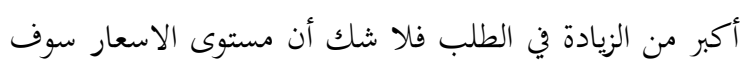
ينخفض. وتلعب الإعانات الاقتصادية والاجتماعية الحكومية دورا مهما في السيطرة على الضغوط التضخمية ومنع ارتفاع الأسعار فعند زيادة حجم الاعانات الاقتصادية تنخفض تكاليف الإنتاج ومن ثم تنخفض الأسعار كذلك فان التوسع في حجم الإعانات

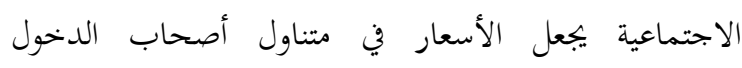
المنخفضة . (الوادي وعزام،151:2007-152) 
العام، وردة الفعل الإيجابية للإنفاق الاستهلاكي والاستثماري

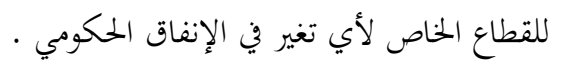

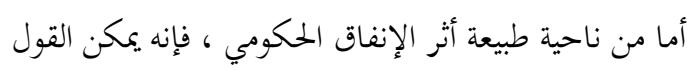

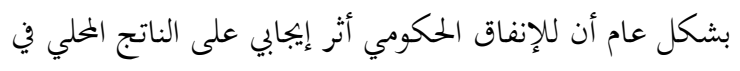

حالة وجود طاقة إنتاجية تضخمية محدودة تساهم في استقرار

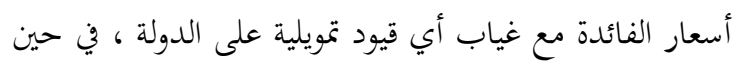

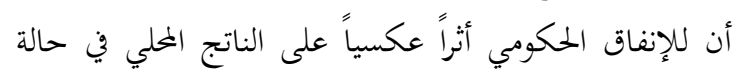

وجود مزاحمة مباشرة أو غير مباشرة ، وصعوبة تمويل الدين العام

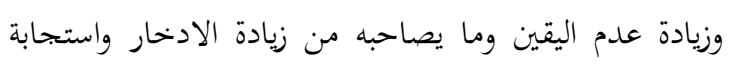

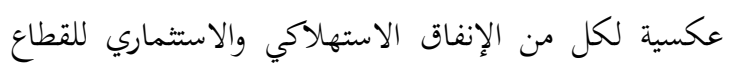

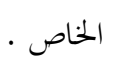
بينما حدد بارو في نموذجه المعدل الأمثل لتدخل الدولة

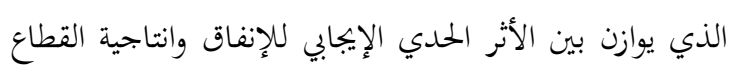

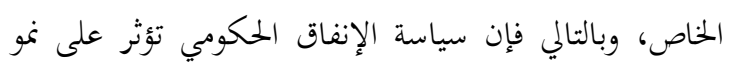

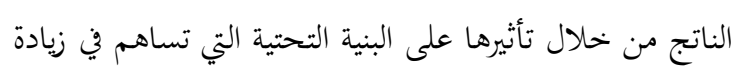

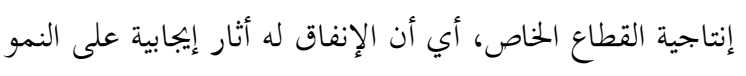

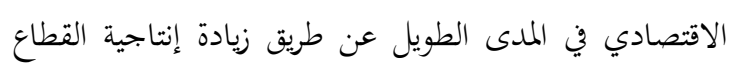

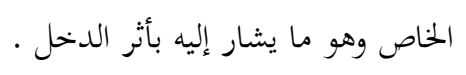

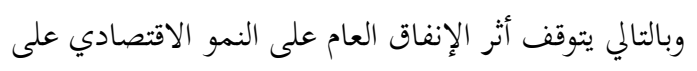

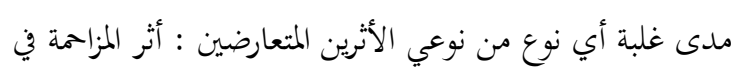

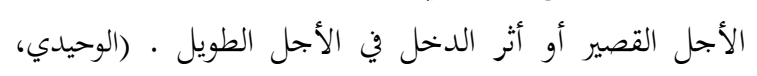

(43-42:2017

\section{4. أثر الانفاق العام على التوازن الخارجي :}

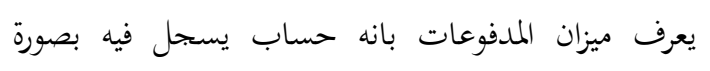

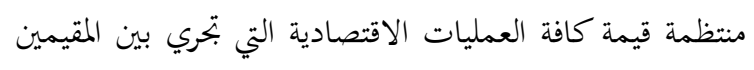

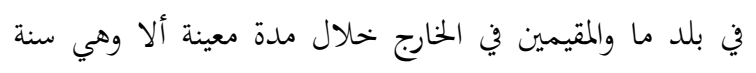

$$
\text { عادة . (حاجي،106:2016) }
$$

وتمارس السياسة الانفاقية الحكومية دوراً كبيراً في التأثير

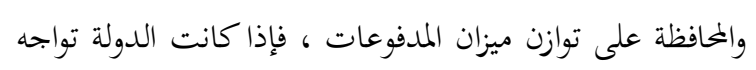

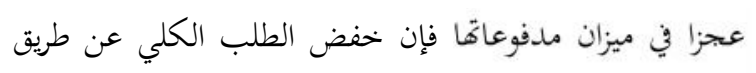
خفض حجم الانفاق العام سوف يؤدي إلى الخفاض أسعار

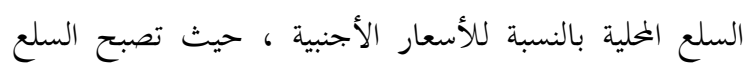

ومن هنا يتضح لنا دور السياسة المالية في التأثير على النمو الاقتصادي والذي يتمثل في التغيير المخطط للإنفاق الحكومي

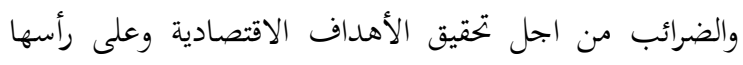

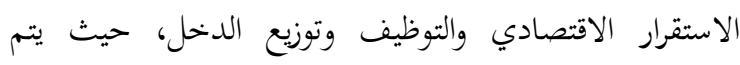

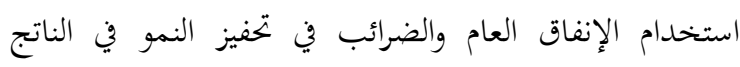
الوطني في أوقات البطالة وانخفاض المستوى العام للأسعار،

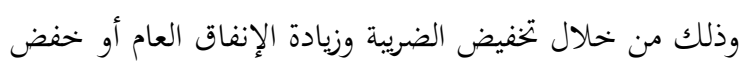
الناتج الوطني في حالة ارتفاع معدل التضخم والخخفاض البطالة وذلك من خلال رفع الضريبة وخفض الإنفاق العام. (محفوظ، (35:2015) وقد أكد أتباع المدرسة الكينزية على أهمية وفعالية الإنفاق

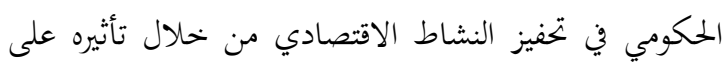
الطلب الكلي، كما أن قيام الدولة ببناء البنى التحتية وانتاج

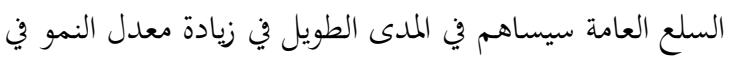
الاقتصاد لكوها عوامل ذات أثر إيجابي على إنتاجية القطاع

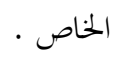
أما من وجهة نظر المدرسة التقليدية الجحديدة فترى عدم

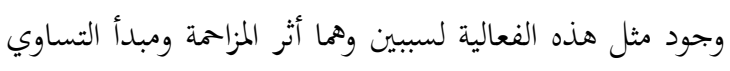

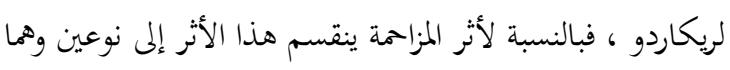

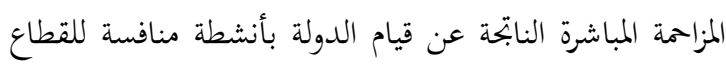

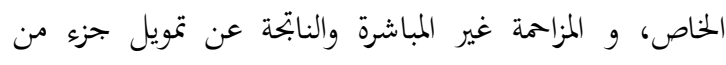

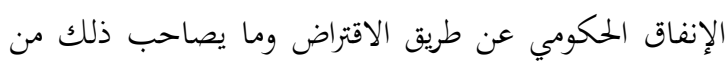

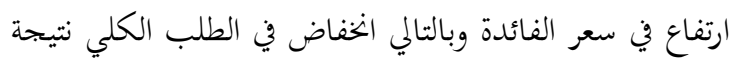

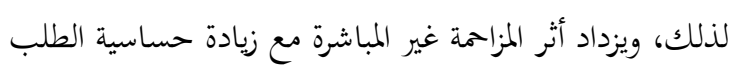
الكلي لتغيرات سعر الفائدة . والواقع أن فاعلية الإنفاق الحكومي كأداة للتأثير على لئل النشاط الاقتصادي تعتمد على عوامل أهمها درجة انفتاح

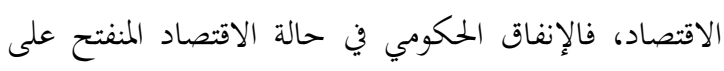
العالم الخارجي ذو فعالية في التأثير على النشاط الاقتصادي، كما أن الإنفاق الحكومي سيكون أكثر فعالية في حالات قصور

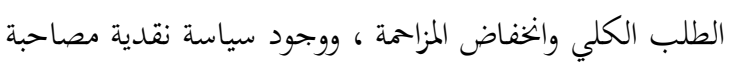

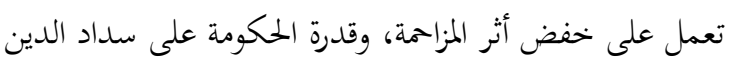


قياس وتحليل أثر الانفاق العام على متغيرات المربع السحري لكالدور

أولاً : تطور اتجاهات الانفاق العام ومعدلات نموها في المملكة العربية السعودية خلال المدة 1991-2017 تكشف المعطيات الواردة في الشكل (2) أن المستويات

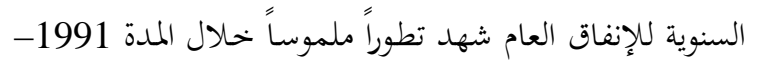
2017 ، إذ ارتفع مـ (485681) مليون ريال سنة 1991 إلى لئل (578181) مليون ريال سنة 2000 ومسن ثم إلى (1652171) مليون ريال سنة 2010 ، وواصل ارتفاعه ليصل في سنة 2017 الى (2425828) مليون ريال، وقد بلغ أعلى قيمة للإنفاق العام

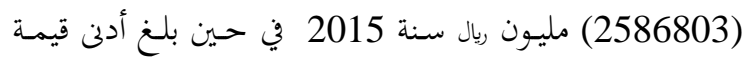

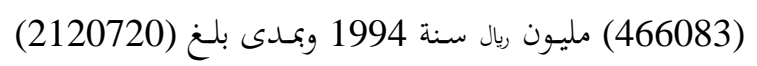

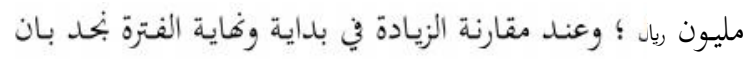
الانفاق العام تضاعف خمسة اضعاف تقريباً ، وبذلك نرى بان وعنان

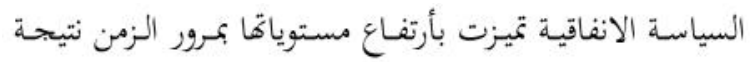
لتوسع دور الحكومة ونشاطها في التأثير على الحياة الاقتصادية

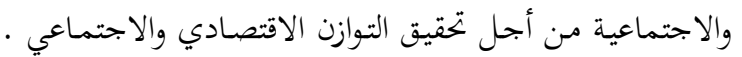

المحلية أكثر تنافسية في الأسواق الدولية مما يؤدي إلى زيادة

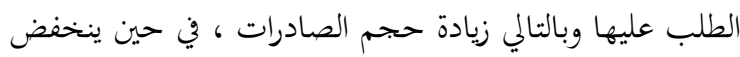
حجم الواردات بسبب ارتفاع أسعار السلع الدولية مقارنة بمثيلتها المحلية، ومع زيادة الصادرات وانخفاض الواردات يتحسن

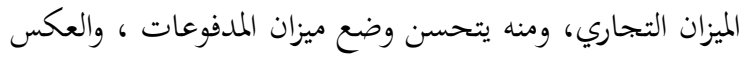

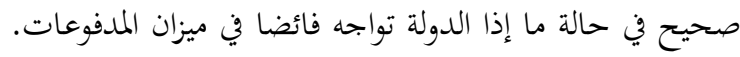
وهكذا تكون السياسة الانفاقية الانكماشية مرغوبا فيها إذا ما

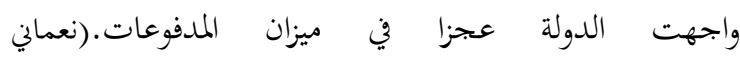
وعبرون، 61:2016)

المبحث الثاني

قياس وتحليل أثر الانفاق العام على متغيرات المربع السحري لكالدور

أولاً : تطور اتجاهات الانفاق العام ومعدلات نموها في الحري المملكة العربية السعودية خلال المدة 1991-2017

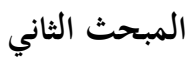

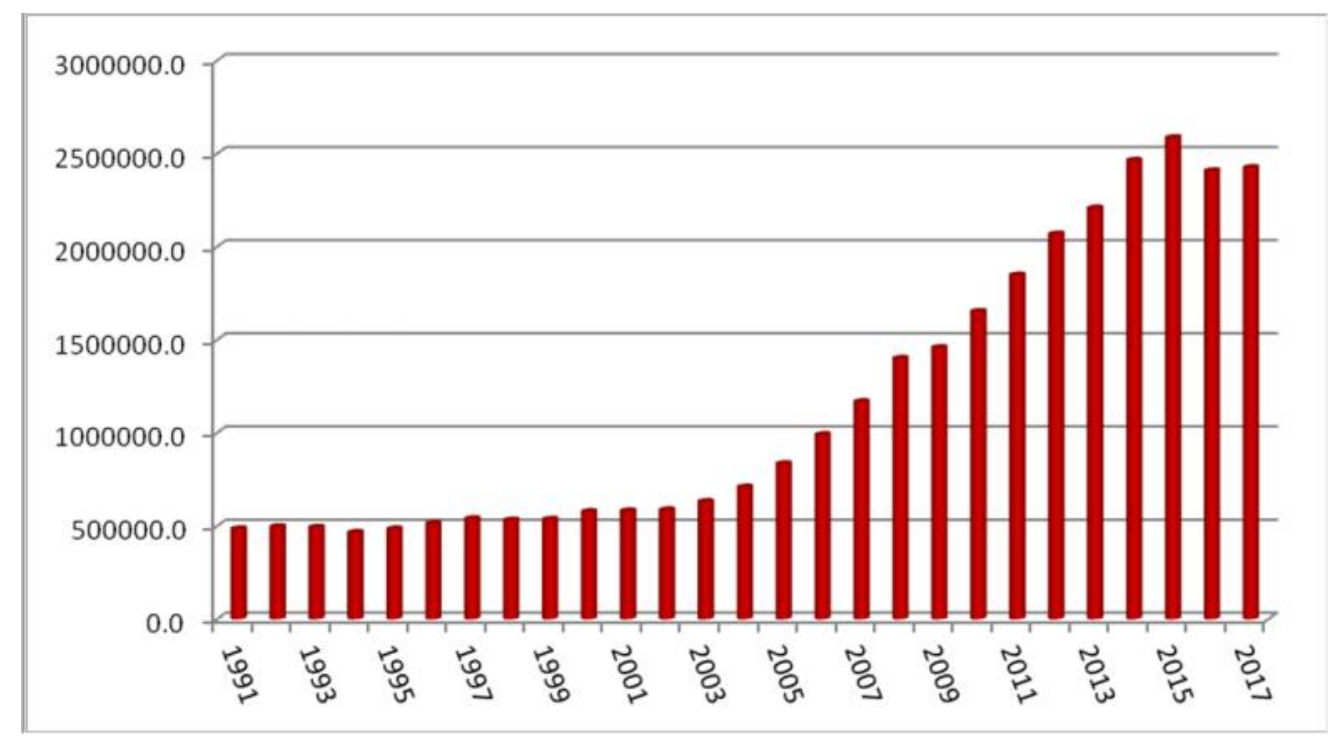

شكل (2): ابتحاهات الانفاق العام في المملكة العربية السعودية خلال المدة 1991-2017 بالاعتماد على بيانات البنك الدولي 


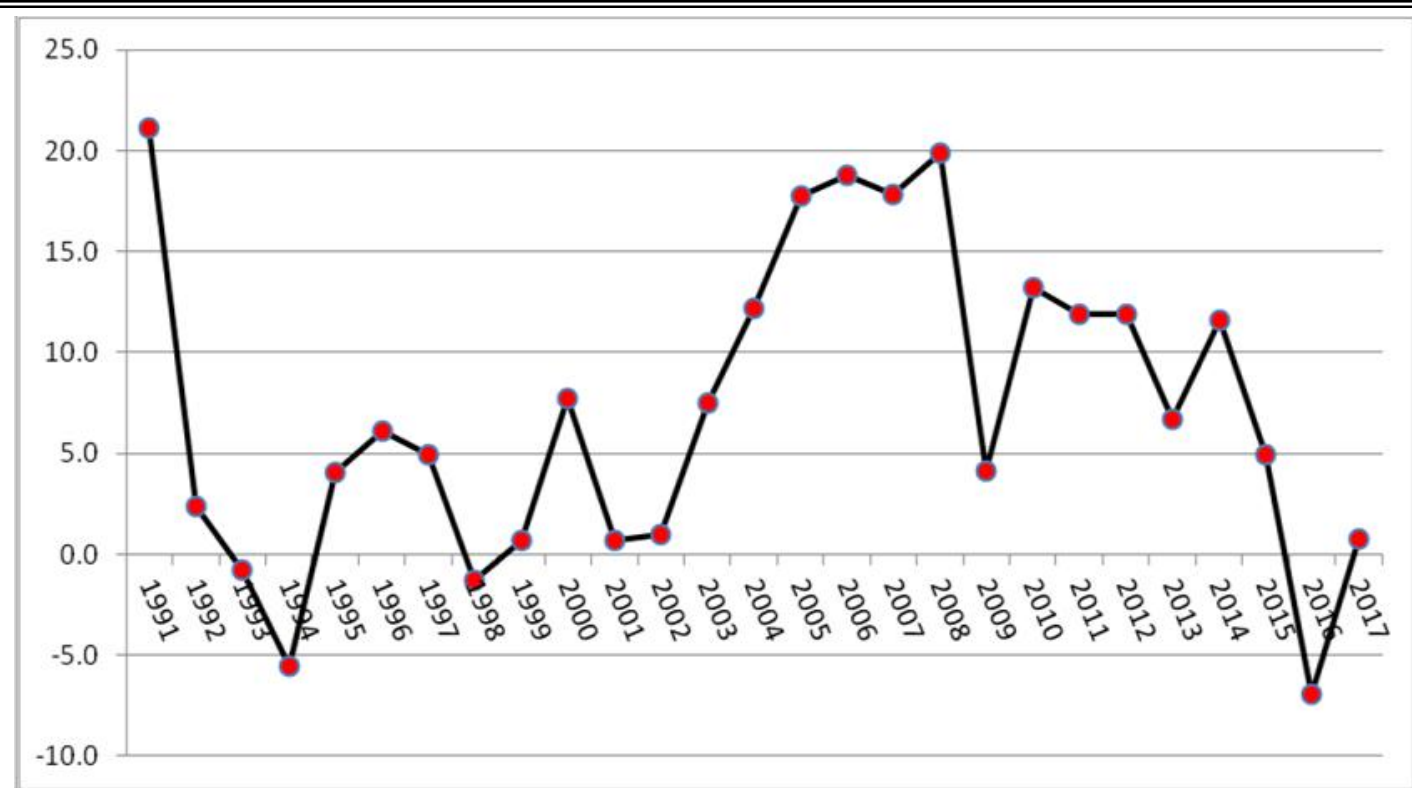

شكل (3): معدلات النمو في الانفاق العام في المملكة العربية السعودية خلال المدة 1991-2017 بالاعتماد على بيانات البنك الدولي

يتبين من الشكل (4) ان ابحاهات متغيرات المربع السحري

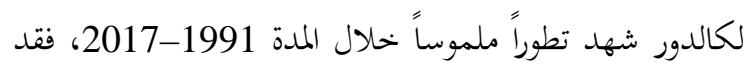

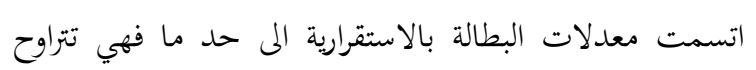

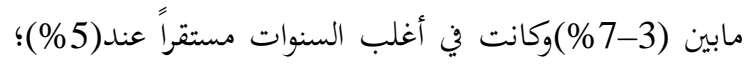
اما فيما يخص التوازن الخارجي (توازن ميزان المدفوعات) فقد واتد

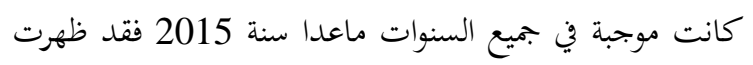

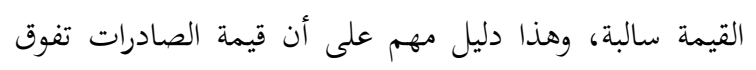
قيمة الواردات في جميع السنوات ماعدا سنة 2015 اذ كانت فئس

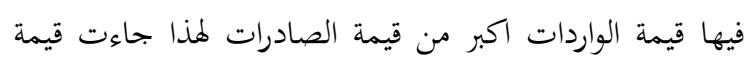

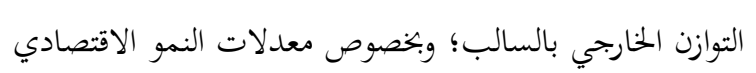
فقد كانت موجبة ونسبتها مرتفعة في اغلب سنوات الدراسة ماعدا السنوات (1993 1998200120092 2016) فقد ظهرت فيها معدلات النمو الاقتصادي سالبة

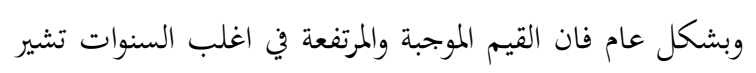

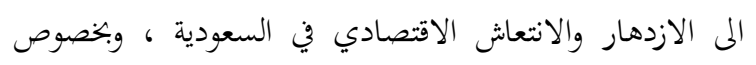

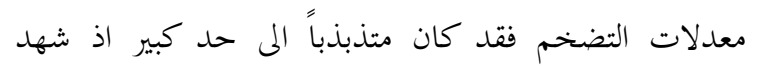
ارتفاعاً ملحوظاً في بعض سنوات الدراسة وقد حاولت الحكومة السعودية السيطرة على معدلات التضخم وخاصة في السنوات
كما ويتبين من الشكل (3) إلى أن المستويات السنوية

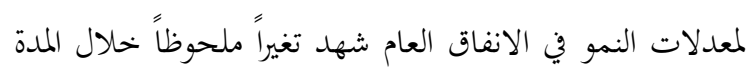

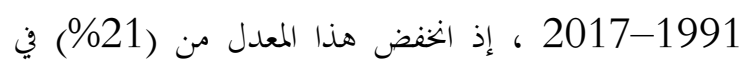

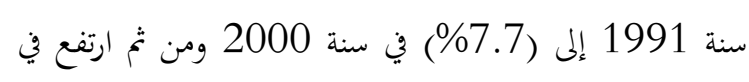

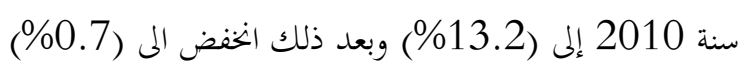
في سنة 2017 ، والملاحظة التي يمكن التركيز عليها من خلال الشكل أن سلوك التغير في معدلات النمو لم يكن منتظماً

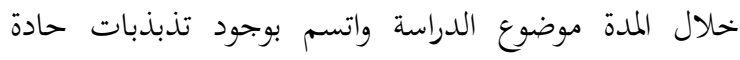

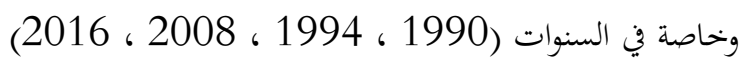
، من جهة أخرى فان معدلات النمو كان سلبياً في اربع سنوات

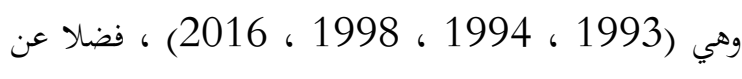

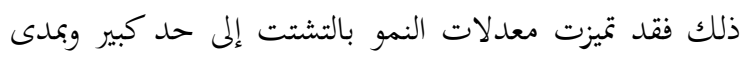

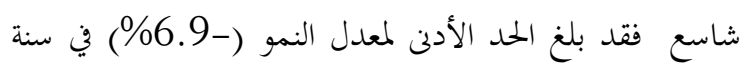

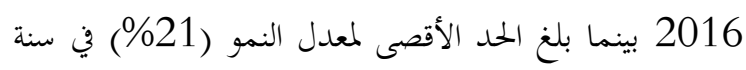
1991 ثانياً: تطور اتجاهات متغيرات المربع السحري لكالدور في المملكة العربية السعودية خلال المدة 1991-2017 
نفس السنة ، وبشكل عام فان أفضل سنة والتي تحققت فيها

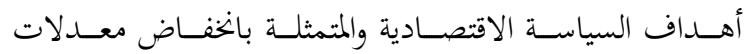

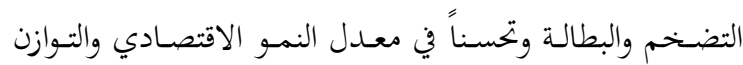

.2003

ت

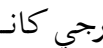
الخ
الاخيرة من الدراسة وخاصة ما بعد سنة 2000، اذ بدأت

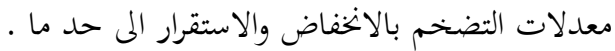

وعند التركيز على محاور المربع السحري نلاحظ ان تحقيق

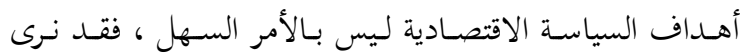

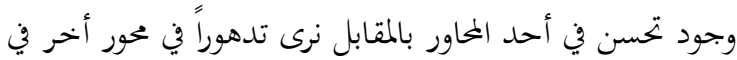
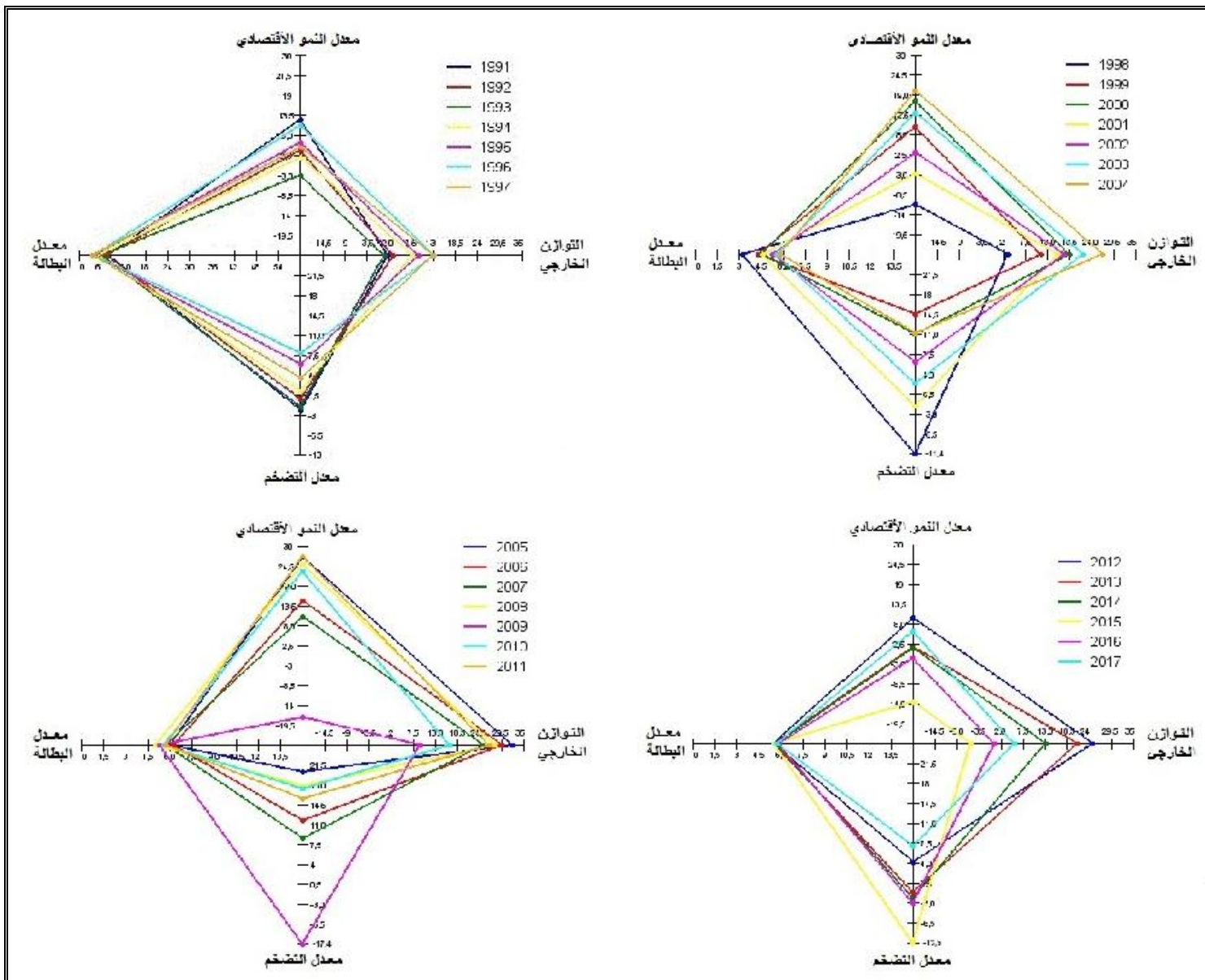

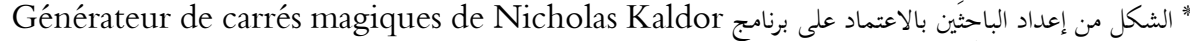
شكل (4) : ابتحاهات متغيرات المربع السحري لكالدور في المملكة العربية السعودية خلال المدة 1991 - 2017 بالائ بالاعتماد على بيانات البنك الدولي

إلى التطبيق (العملي) سنستعين بالاقتصاد القياسي الذي يضفي على العلاقات الوصفية سمة التقريب الواقعي كما يعمل على

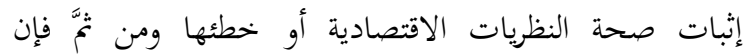

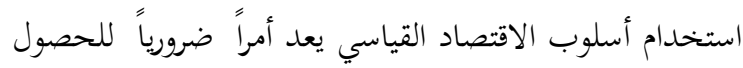

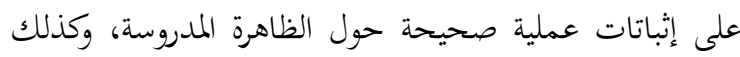
للتأكد من صحة الفرضيات والعلاقات السلوكية بين المتغيرات
ثالثاً : تحليل أثر الانفاق العام على متغيرات المربع السحري لكالدور في المملكة العربية السعودية

نحاول في هذا الجزء من الدراسة الوقوف على تأثير نمو

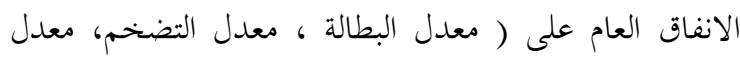
النمو الاقتصادي والتوازن الخارجي ) في المملكة العربية السعودية، ولإثبات فرضيات الدراسة ونقلها من الواقع النظري 
Y بنسبة مئوية

ب : معدل التضخم وهو يمثل المتغير المعتمد الثاني وقد عبرنا

$$
\text { عنه بنسبة مئوية }
$$

Y3

$$
\text { وقد عبرنا عنه بنسبة مئوية }
$$

YY

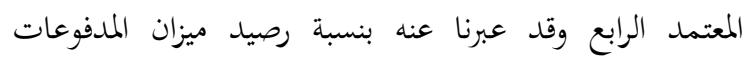

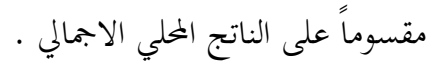
Ui

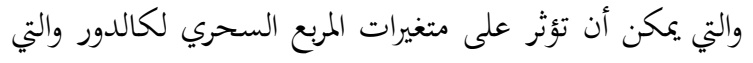

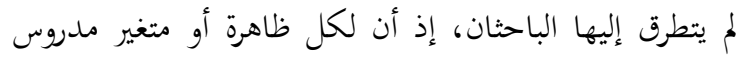

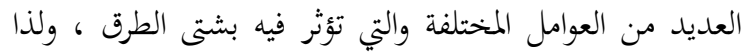

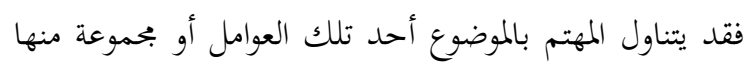
وحسب متطلبات الدراسة لكنه بدون شك لن يكون قادراً

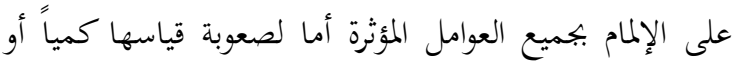

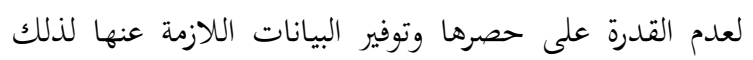
يستعاض عنها بالمتغير (U) والذي يعبر عن تلك المتغيرات . 2. تحديد فترة الإبطاء الملائمة :

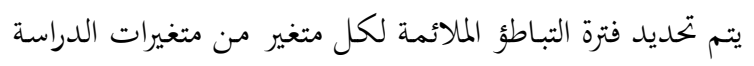

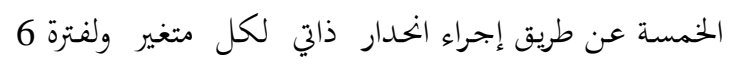

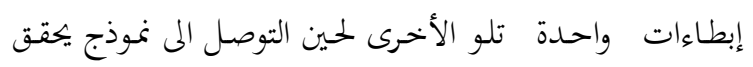
أفضل قيم للمعايير (HQ SC AIC) وكانت النتائج كما

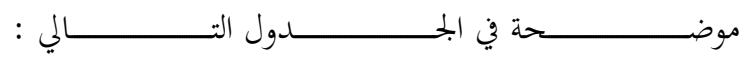

المقاسة، واتساقاً مع ذلك تم الاعتماد على نموذج الانحدار Auto-regressive Distributed Lag Modelsالاحصائي والذي يتضمن تحليل أثر الانفاق العام على متغيرات المربع السحري لكالدور .

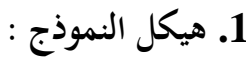
يتكون النموذج من معادلة انحدار خطي بسيط يتضمن متغير مستقل متمثل بالانفاق العام وبحموعة من المتغيرات المعتمدة وهي ( معدل البطالة ، معدل التضخم ، معدل النمو

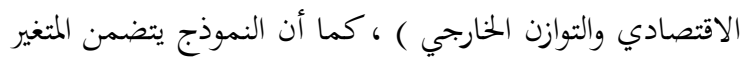

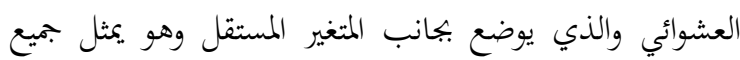
المتغيرات الأخرى التي تؤثر على المتغير المعتمد والتي لم يتم

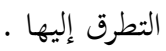
$\mathrm{Y}_{1}=\mathrm{F}(\mathrm{X})$

$\mathrm{Y}_{2}=\mathrm{F}(\mathrm{X})$

$\mathrm{Y}_{3}=\mathrm{F}(\mathrm{X})$

$\mathrm{Y}_{4}=\mathrm{F}(\mathrm{X})$ وإن الصيغة القياسية للنموذج هي :

$\mathrm{Y}_{1}=\mathrm{b}_{0}+\mathrm{b}_{1} \mathrm{X}+\mathrm{U}_{\mathrm{i}}$ $\mathrm{Y}_{2}=\mathrm{b}_{0}+\mathrm{b}_{1} \mathrm{X}+\mathrm{U}_{\mathrm{i}}$ $\mathrm{Y}_{3}=\mathrm{b}_{0}+\mathrm{b}_{1} \mathrm{X}+\mathrm{U}_{\mathrm{i}}$ $\mathrm{Y}_{4}=\mathrm{b}_{0}+\mathrm{b}_{1} \mathrm{X}+\mathrm{U}_{\mathrm{i}}$

إذ يعبر : n ع : معدل نمو الانفاق العام وهو يمثل المتغير المستقل وقد عبرنا عنه بنسبة مئوية 
جسدول (1): ننائج اختبار Lag Length Criteria

\begin{tabular}{|c|c|c|c|c|}
\hline $\begin{array}{c}\text { Hannan-Quinn } \\
\text { information criterion } \\
\mathrm{HQ}\end{array}$ & $\begin{array}{c}\text { Schwarz information } \\
\text { criterion } \\
\text { SC }\end{array}$ & $\begin{array}{c}\text { Akaike information } \\
\text { criterion } \\
\text { AIC }\end{array}$ & $\begin{array}{c}\text { عدد التباطؤ لكل متغير } \\
\text { Lag }\end{array}$ & المتغيرات \\
\hline $6.568158^{*}$ & $6.646047^{*}$ & $6.546569^{\star}$ & 1 & $x$ \\
\hline $1.084777^{*}$ & $1.162666^{*}$ & 1.063187 & 1 & $\mathrm{y}_{1}$ \\
\hline $8.021956^{*}$ & $8.060901^{*}$ & $8.011162^{*}$ & 0 & $\mathrm{y}_{2}$ \\
\hline $8.021956^{*}$ & $8.060901^{*}$ & $8.011162^{*}$ & 0 & $\mathrm{y}_{3}$ \\
\hline $7.048722^{\star}$ & $7.126611^{\star}$ & $7.027132^{*}$ & 1 & $y_{4}$ \\
\hline
\end{tabular}

المصدر : الجمدول من إعداد الباحثَنْ بالاعتماد على مخرجات برنامج Eviews

المعتمدة في هذه الدراسة بأستخدام أختبار جذر الوحدة ، ورغم تعدد أختبارات جذر الوحدة فسيتم الأعتماد على أختبار ديكي فولر الموسع (ADFmented Dickey-Fuller (a) للتأكد من وجود جذر الوحدة من عدمه في بيانات الدراسة ،

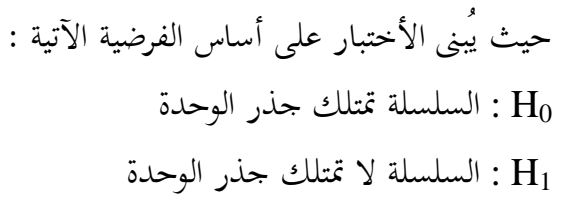

وبعـد تغذيسة برنـامج Eviews بييانـات الدراسـة وإجـراء

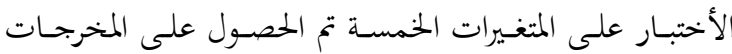
: أدول (لجة في
يُظهر الجحدول (1) أن أفضل فترة إبطاء ملائمة للمتغيرات

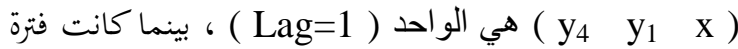
الإبطاء الملائمة للمتغيرين (

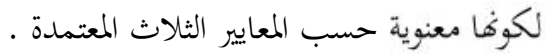
3. اختبار استقرارية متغيرات الدراسة :

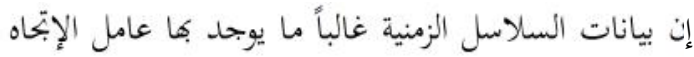
العام الذي يعكس بعض الظروف التي تؤثر على المتغير وبتعله ينحدر على نفس النمط لذا يُفترض التخلص من هذا الاتحاه

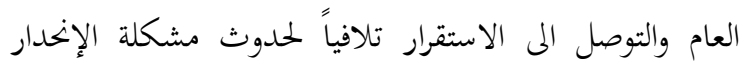

\begin{tabular}{|c|c|c|c|c|c|c|c|}
\hline & \multicolumn{3}{|c|}{ الفرق الاول ( 1st difference ) } & \multicolumn{3}{|c|}{ المستوى ( Level ) } & \\
\hline & Noon & $\begin{array}{c}\text { Trend \& } \\
\text { Intercept }\end{array}$ & Intercept & Noon & $\begin{array}{c}\text { Trend \& } \\
\text { Intercept }\end{array}$ & Intercept & \\
\hline & -1.9550 & -3.6032 & -2.9862 & -1.9544 & -3.5950 & -2.9810 & \\
\hline \multirow{2}{*}{ المستوى (0) المستقرة عند } & $\ldots$ & $\ldots$ & $\ldots$ & -2.5266 & -3.2031 & -3.0304 & $x$ \\
\hline & $\cdots$ & $\ldots$. & .... & 0.0137 & 0.1057 & 0.0451 & Prob. \\
\hline \multirow{2}{*}{$\begin{array}{c}\text { مستقرة عند الفرق الأول } \\
\text { I(1) }\end{array}$} & -3.1009 & -3.1014 & -3.0419 & -1.2812 & -3.4293 & -2.8644 & $\mathrm{y}_{1}$ \\
\hline & 0.0033 & 0.1275 & 0.0446 & 0.1793 & 0.0692 & 0.0634 & Prob. \\
\hline \multirow[t]{2}{*}{ مستقرة عند المستوى (0) I) } & $\cdots$ & $\cdots$ & $\cdots$ & -4.0762 & -4.5640 & -4.6537 & $\mathrm{y}_{2}$ \\
\hline & $\ldots$ & $\ldots$ & $\ldots$ & 0.0002 & 0.0063 & 0.0010 & Prob. \\
\hline
\end{tabular}
الزائف بين المتغيرات . إذ سيتم أختبار أستقرارية السلاسل جـدول (2): نتائج اختبار ديكي فولر الموسع لحذر الوحدة قبل الاستقرارية وبعد الاستقرارية لمتغيرات الدراسة خلال المدة ( 1991-2017 ) 


\begin{tabular}{|c|c|c|c|c|c|c|c|}
\hline \multirow[t]{2}{*}{ مستقرة عند المستوى (0) } & $\ldots$ & $\ldots$ & $\ldots$ & -3.4637 & -4.2686 & -4.3550 & $\mathrm{y}_{3}$ \\
\hline & $\ldots$ & $\ldots$ & $\ldots$ & 0.0013 & 0.0121 & 0.0022 & Prob. \\
\hline \multirow{2}{*}{ مستقرة عند الفرق الأول } & -4.9942 & -4.3725 & -4.8888 & -1.0226 & -1.7596 & -2.0270 & $y_{4}$ \\
\hline & 0.0000 & 0.0115 & 0.0006 & 0.2676 & 0.6948 & 0.2742 & Prob. \\
\hline
\end{tabular}

المصدر : الجدول من إعداد الباحيُّنِ بالاعتماد على مخرجات برنامج Eviews

4. تطبيق منهجية الانحدار الذاتي للفجوات الزمنية الموزعة : ARDL Autoregressive Distributed Lag Estimate

توجد العديد من الطرق المستخدمة لدراسة التكامل المشترك

ما بين المتغيرات والأكثرها شيوعاً أختبار أبخل غرابخر ( Engle

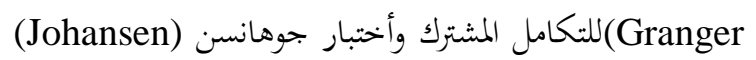

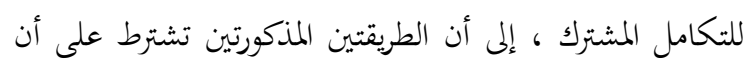

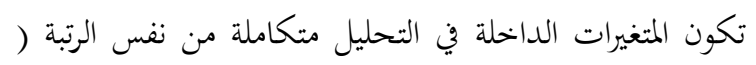

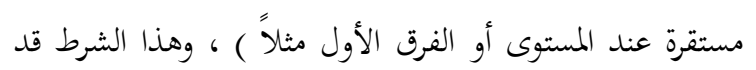

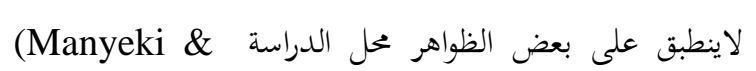

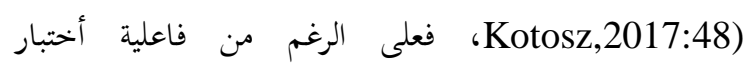

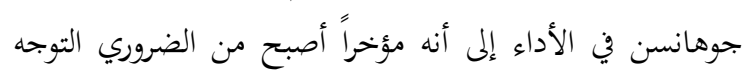
لنماذج تكون ذات مرونة أكثر لتناسب الظواهر التي لايمكن

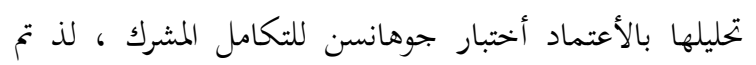
أقتراح تقنية للإنحدار الذاتي سميت بنموذج ARDL التئيار التي يمكنها

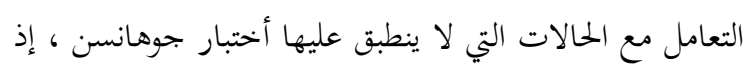

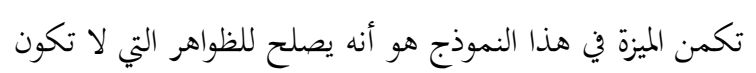

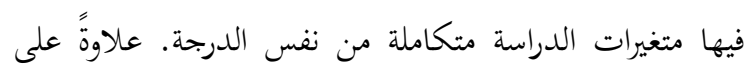
ذلك تمتاز تقنية ARDL بمرونتها العالية وهي تعطي تقديرات واقعية وفعالة وهو يناسب الدراسة الحالية . N N (Uko,2016:76 إن تركيب نموذج ARDL ناتج عن دمج نماذج الانحدار الذاتي Autoregressive Model مع نماذج البطاء الموزعة

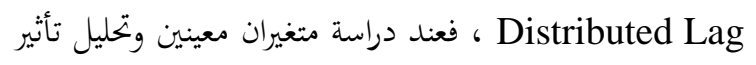
المتغير المستقل X على التغيرات الحاصلة في المتغير المعتمد لفأنه

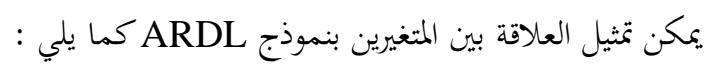

الجددول (2) السابق يمثل ملخص لنتائج الأستقرارية لجميع متغيرات الدراسة ويُلاحظ أن المتغير x الذي يمثل نمو الإنفاق العام والمتغير y2 الذي يمثل التضخم والمتغير y3 الذي يمثل

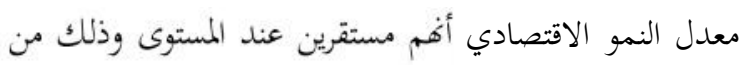
خلال مقارنة القيمة المطلقة المخسوبة لهم مع القيمة المطلقة

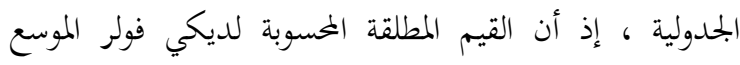
للمتغيرات الثلاثة ولنماذج الثلاثة هي أكبر من القيم المطلقة

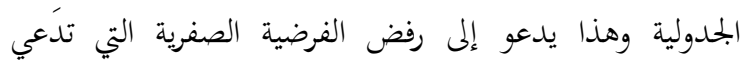

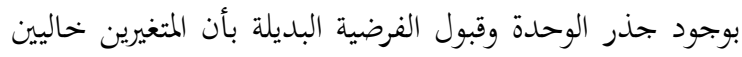

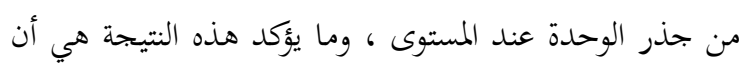

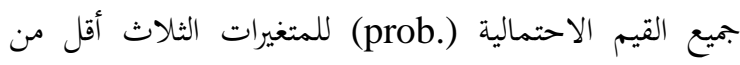
مستوى الدلالة الإحصائية 5\% ، إذن فأن المتغيرات ( منمو لماتهيه

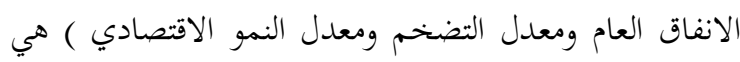
متكاملة من الدرجة صفر (0) I(0)

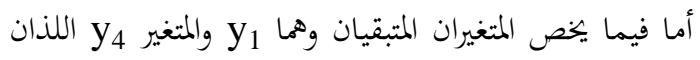

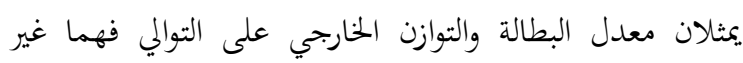

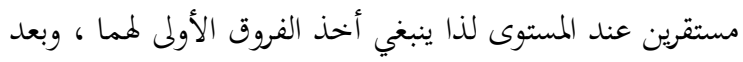

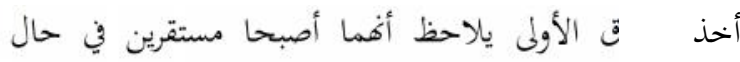

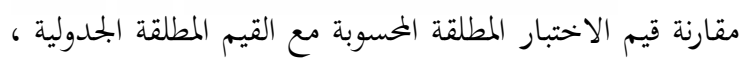

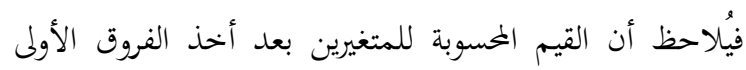

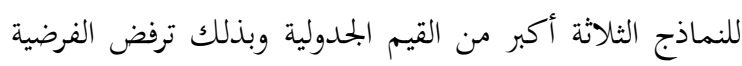

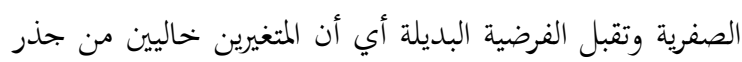

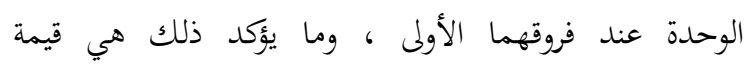
الاحتمالية (prob.) التي تكون أقل من مستوى الدوف الدلالة الإحصائية 5\% ، وبهذا فإن المتغيران (معدل البطالة والتوازن

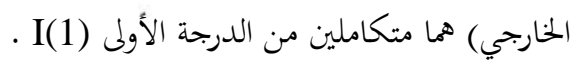


إت التي تحقق التكامل المشترك بينها يعني أخا

تعكس علاقة توازنية طويلة الأجل ، وبعد توفر المتطلبات المالائمة والضرورية من ناحية درجة التكامل للمتغيرات فيمكن

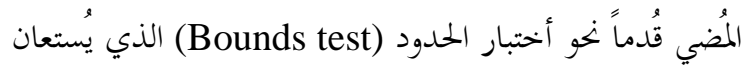
به لاختبار التكامل المشترك بين المتغيرات المعتمدة الأربعة ( معدل البطالة ، معدل التضخم ، معدل النمو الاقتصادي و التوازن الخارجي ) هل لما علاقة تكامل مشترك مع المتغير المستقل (نمو الإنفاق العام) أم لا ، إذ تم بناء الاختبار

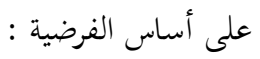
لا يوجد علاقة تكامل مشترك بين المتغيرين يوجد علاقة تكامل مشترك بين المتغيرين وبعد تطبيق اختبار Bound تم الحصول على النتائج المبينة

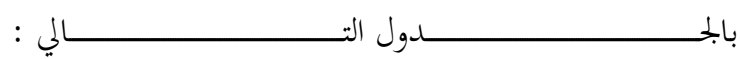

$\Delta y_{i}=\alpha_{0}+\alpha_{1} x_{t-1}+\alpha_{2} y_{t-1}$

$$
+\sum_{i=0}^{k} b_{1} \Delta x_{t-j}+\sum_{i=0}^{k} b_{1} \Delta y_{t-j}+U_{i}
$$

حيث يلاحظ أن النموذج هو عبارة عن دالة في الإبطاءات

$$
\text { الزمنية لمتغيراته ـ (حمدلله، 84:2018) }
$$

لذا بعد الانتهاء من دراسة أستقرارية متغيرات الدراسة والتأكد من درجة تكامل المتغيرات التي ظهرت بأفا متكاملة من الدرجة صفر وأخرى من الدرجة الأولى، فبالإمكان الآن الانتقال إلى الخطوة التالية وهي تطبيق تقنية ARDL للتكامل

$$
\text { المشترك على متغيرات الدراسة . }
$$

\begin{tabular}{|c|c|c|c|c|c|c|}
\hline \multirow[t]{2}{*}{ النيجة } & \multicolumn{3}{|c|}{$\begin{array}{c}\text { القيم الجدولية للاختبار } \\
\text { Critical Value Bounds }\end{array}$} & \multirow[t]{2}{*}{ القيمة المحسوبة } & \multirow[t]{2}{*}{ عدد المتغيرات } & \multirow[t]{2}{*}{ النموذج } \\
\hline & $\begin{array}{l}\text { الحد الأعلى } \\
\text { I1 Bound }\end{array}$ & $\begin{array}{l}\text { الحد الأدنى } \\
\text { I0 Bound }\end{array}$ & $\begin{array}{c}\text { مستوى المعنوية } \\
\text { Significance }\end{array}$ & & & \\
\hline لا يوجد تكامل مشترك & 5.73 & 4.94 & $\% 5$ & 4.4342 & 1 & $\left(y_{1}, x\right)$ \\
\hline يوجد تكامل مشترك & 5.73 & 4.94 & $\% 5$ & 23.3448 & 1 & $\left(y_{2}, x\right)$ \\
\hline يوجد تكامل مشترك & 5.73 & 4.94 & $\% 5$ & 12.2378 & 1 & $\left(y_{3}, x\right)$ \\
\hline يوجد تكامل مشترك & 5.73 & 4.94 & $\% 5$ & 14.3933 & 1 & $\left(y_{4}, x\right)$ \\
\hline
\end{tabular}

5. اختبار التكامل المشترك وفق منهجية نموذج الانحدار الذاتي للفجوات الزمنية الموزعة :

Eviews المصدر : الجدول من إعداد الباحثَين بالاعتماد على مخرجات برنامج

أما في ما يتعلق بالنموذج الثاني (y2,x) فيلاحظ أن قيمة الاختبار المحسوبة F-statistic للنموذج هي (23.3448) وهي أكبر من قيمة الحد الأدنى الجدولية ل (4.94) ، وكذلك الحال بالنسبة للنموذج الثالث (y, قيمة الاختبار المسوبة F-statistic (12.2378) هي أكبر من قيمة الحد الأدنى الجدولية ل Bound I0 (4.94)، وللنموذج الرابع (y4,x) قيمة الاختبار المحسوبة له (14.3933)

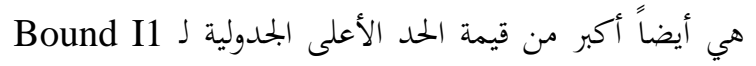
(5.73) عند مستوى معنوية 5\% وهذه النتائج تدعم رفض
يعتمد اختبار الحدود للتكامل المشترك بين المتغيرات التابعة والمتغير والمستقل على القيمة الإحصائية F-statistic للنماذج الأربعة الموضحة في الجمدول (3) وبناءاً عليه تبين مايأتي : بالنسبة للنموذج الأول (y, $)$ يلاحظ أن القيمة المسوبة لاختبار F-statistic (4.4342) هي أقل من قيمة الحد الأعلى الجحدولية ل Bound I1 (5.73) عند مستوى معنوية \%5 ، وهذا يدل على عدم وجود علاقة تكامل مشترك بين متغير البطالة لy1 ومتغير نمو الانفاق العام X ل 
فرضية العدم والدلالة على وجود علاقة تكامل مشترك بين 6RDL قصير الأجل وطويل الأجل : تقدير نموذج

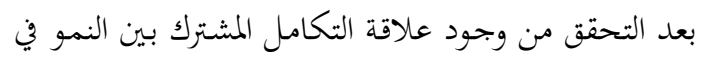

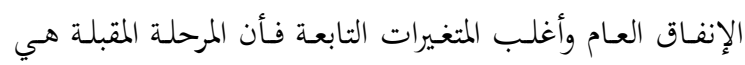
المتغيرات للنماذج الثلاث ( الثاني ، الثالث والرابع ).

تقدير نموذج تصحيح الخطأ غير المقيد (ARDL-UECM)

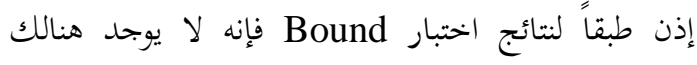

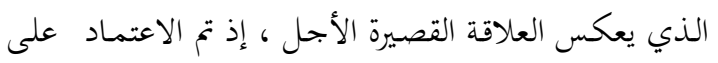
علاقة طويلة الأجل تتجه من المتغير المستقل(نمو الإنفاق العام)

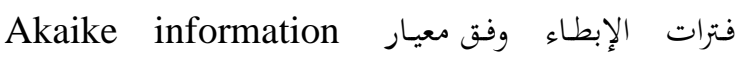

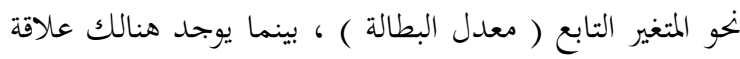
criterion (AIC)

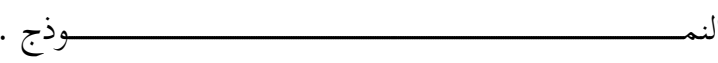

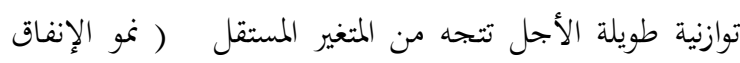

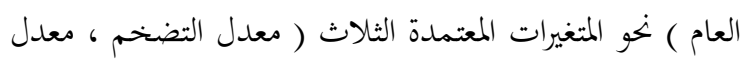
النمو الاقتصادي والتوازن الخارجي).

جدول (4): نتائج تقدير نموذج قصير الأجل Cointegrating Form بتقنية ARDL

\begin{tabular}{|c|c|c|c|c|c|}
\hline $\begin{array}{l}\text { المعنوية } \\
\text { Prob. }\end{array}$ & $\begin{array}{c}\text { t قيمة } \\
\text { t-Statistic }\end{array}$ & $\begin{array}{l}\text { الخطأ المعياري } \\
\text { Std. Error }\end{array}$ & $\begin{array}{c}\text { المعلمة } \\
\text { Coefficient }\end{array}$ & $\begin{array}{c}\text { المتغير } \\
\text { Variable }\end{array}$ & $\begin{array}{c}\text { النموذج القصير الأجل } \\
\text { Cointegrating Form }\end{array}$ \\
\hline 0.4719 & -0.7320 & 0.0137 & -0.0100 & $\mathrm{D}(\mathrm{X})$ & \multirow[t]{2}{*}{ تأثير نمو الإنفاق العام على معدل البطالة } \\
\hline 0.0227 & -2.4509 & 0.1987 & -0.4871 & CointEq(-1) & \\
\hline 0.0001 & 4.9138 & 0.2452 & 1.2047 & $\mathrm{D}(\mathrm{X})$ & \multirow{2}{*}{ تأثير نمو الإنفاق العام على معدل التضخم } \\
\hline 0.0000 & -6.5901 & 0.1766 & -1.1641 & CointEq(-1) & \\
\hline 0.1913 & 1.3525 & 0.1570 & 0.2123 & $\mathrm{D}(\mathrm{Y} 3(-1))$ & \multirow{3}{*}{ تأثير نمو الإنفاق العام على النمل } \\
\hline 0.0000 & 6.2903 & 0.2716 & 1.7084 & $\mathrm{D}(\mathrm{X})$ & \\
\hline 0.0001 & -4.7272 & 0.2806 & -1.3266 & CointEq(-1) & \\
\hline 0.0057 & 3.3087 & 0.4140 & 1.3697 & $\mathrm{D}(\mathrm{DY} 4(-1))$ & \multirow{7}{*}{ تأثير نمو الإنفاق العام على الثوازن } \\
\hline 0.0148 & 2.8095 & 0.3011 & 0.8461 & D(DY4(-2)) & \\
\hline 0.0092 & 3.0544 & 0.1970 & 0.6020 & $\mathrm{D}(\mathrm{DY} 4(-3))$ & \\
\hline 0.0011 & 4.1662 & 0.2307 & 0.9612 & $\mathrm{D}(\mathrm{X})$ & \\
\hline 0.3012 & 1.0766 & 0.3158 & 0.3399 & $\mathrm{D}(\mathrm{X}(-1))$ & \\
\hline 0.1486 & 1.5355 & 0.3146 & 0.4831 & $\mathrm{D}(\mathrm{X}(-2))$ & \\
\hline 0.0002 & -5.1810 & 0.5498 & -2.8485 & CointEq(-1) & \\
\hline
\end{tabular}

المصدر : الجدول من إعداد الباحَّين بالاعتماد على مخرجات برنامج Eviews

علاقة معنوية موجبة بين متغير نمو الإنفاق العام الذي يفسر متغير معدل التضخم كما يؤشر ذلك القيمة الاحتمالية

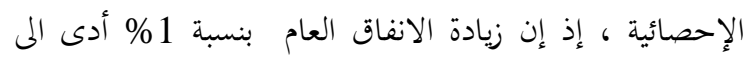

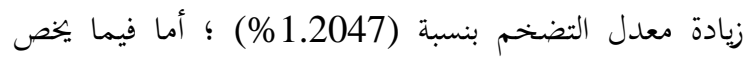
النموذج الثالث للأجل القصير يلاحظ أن هنالك تأثير واضح

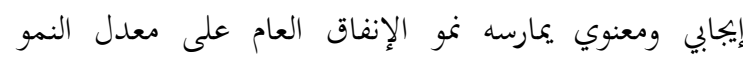

يتبين من نتائج المعلمات القصيرة الاجل المقدرة للنموذج الأول والمعروضة في جدول (4) أن للانفاق العام أثراً سلبياً

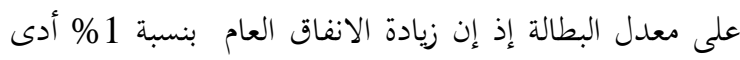

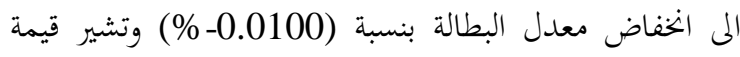
المعنوية الإحصائية (prob.) بانها غير معنوية ؛ بينما كانت

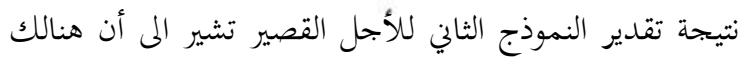


عند تخلفاته الأولى والثانية والثالثة على عكس معلمات المتغير

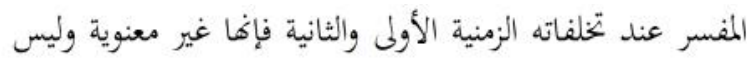
لها تأثير ملحوظ على المتغير التابع كون القيم الاحتمالية لها

$$
\text { أكبر من المعنوية الإحصائية 55\% . }
$$

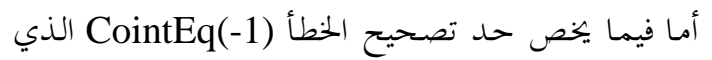

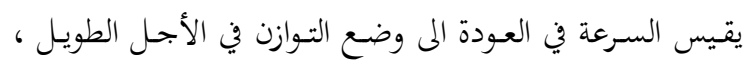

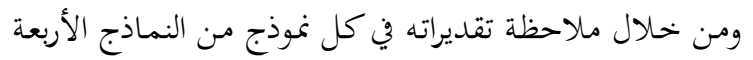

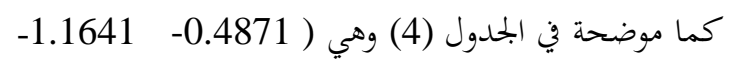
1.3266-

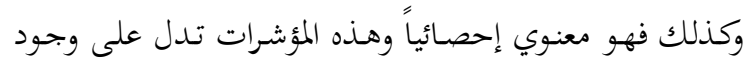

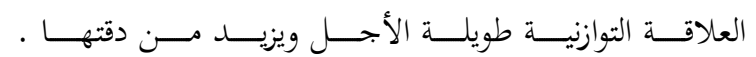

الاقتصادي كما تؤشره قيمة المعنوية الإحصائية لمعلمة المتغير

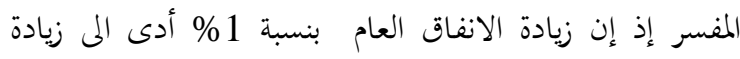
معدل النمو الاقتصادي بنسبة (1.7084\%) على عكس إدس إنس

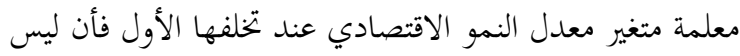

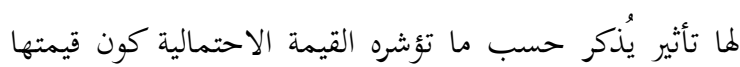

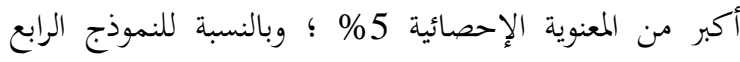
للأجل القصير يتضح بأنه هنالك علاقة معنوية لتأثير نمو الإنفاق العام على التغيرات التي تحصل في التوازن الخارجي

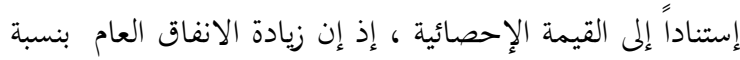

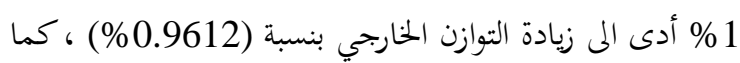
يوجد هنالك تأثير معنوي تفسره معلمات متغير التوازن الخارجي التوني

جدول (5): نتائج تقدير نموذج طويل الأجل Long Run Coefficients بتقنية ARDL

\begin{tabular}{|c|c|c|c|c|c|}
\hline المعنوية & قيمة & الخطأ المعياري & المعلمة & المتغير & النموذج الطويل الأجل \\
\hline Prob. & t-Statistic & Std. Error & Coefficient & Variable & Long Run Coefficients \\
\hline 0.5326 & -0.6340 & 0.0325 & -0.0206 & $\mathrm{X}$ & تأثير نمو الإنفاق العام على البطالة \\
\hline 0.7350 & 0.3428 & 0.2983 & 0.1023 & C & \\
\hline 0.0137 & 2.6791 & 0.1937 & 0.5189 & $X$ & تأثير نمو الإنفاق العام على التضخم \\
\hline 0.5703 & 0.5763 & 1.8487 & 1.0654 & C & \\
\hline 0.0004 & 4.2053 & 0.1853 & 0.7791 & $X$ & تأثير نمو الإنفاق العام على معدل النمو الاقتصادي \\
\hline 0.2258 & 1.2499 & 1.7110 & 2.1386 & C & \\
\hline 0.2221 & -1.2825 & 0.0804 & -0.1031 & $X$ & تأثير نمو الإنفاق العام على التوازن الخارجي \\
\hline 0.2531 & 1.1960 & 0.7455 & 0.8916 & C & \\
\hline
\end{tabular}

المصدر: الجدول من إعداد الباحَين بالاعتماد على مخرجات برنامج Eviews

بعد تقدير العلاقة القصيرة الأجل يتم قياس العلاقة طويلة (0.0206-\%)وانخفاض التوازن الخارجي بنسبة(0.1031-0\%) إضافة إلى أن المعلمتين غير معنويتين إحصائياً من خلال مقارنة

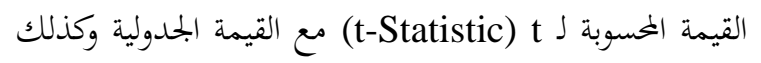
من خلال قيمتهما الاحتمالية (Prob.) التي ظهرت أكبر من المعنوية الإحصائية \%5\% . بينما لوحظ هنالك تأثير إيجابي ومعنوي يتجه من نمو الإنفاق العام نخو معدل التضخم ومعدل النمو الاقتصادي على المدى الطويل ، إذ إن زيادة الانفاق العام بنسبة 1\% أدى الى زيادة معدل التضخم بنسبة (0.5189\%)
الأجل في إطار نموذج ARDL وتتضمن هذه العملية الحصول على تقديرات المعلمات في الأجل الطويل كما هو موضح في الجدول (5) (5) (2)

تشير نتائج معلمات الأجل الطويل كما في الجدول (5) إلى التأثير السلبي الذي يسببه نمو الإنفاق العام على معدل البطالة والتوازن الخارجي على المدى الطويل ، إذ إن زيادة الانفاق العام بنسبة 1\% أدى الى انخفاض معدل البطالة بنسبة 


$$
\begin{aligned}
\mathrm{y}_{2}= & 1.0654+1.2047 \mathrm{D}(\mathrm{x})-1.1641+0.5189 \mathrm{x} \\
\mathrm{y}_{3}= & 2.1386+0.2123 \mathrm{D}\left(\mathrm{y}_{3}(-1)\right)+1.7084 \mathrm{D}(\mathrm{x})- \\
& 1.3266+0.7791 \mathrm{x} \\
\mathrm{Dy}_{4}= & 0.8916+1.3697 \mathrm{D}\left(\mathrm{Dy}_{4}(-1)\right)+0.8461 \mathrm{D}\left(\mathrm{Dy}_{4}(-\right. \\
& 2))+0.6020 \mathrm{D}\left(\mathrm{Dy}_{4}(-3)\right)+0.9612 \mathrm{D}(\mathrm{x})+ \\
& 0.3399 \mathrm{D}(\mathrm{x}(-1))+0.4831 \mathrm{D}(\mathrm{x}(-2))-2.8485- \\
& 0.1031 \mathrm{x}
\end{aligned}
$$$$
\text { والتقييم الإحصائي لهذه النماذج الأربعة قد تم تبويبها في }
$$

وزيادة معدل النمو الاقتصادي بنسبة (0.7791\%)، وما يؤشر

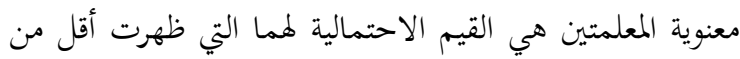
مستوى الدلالة الإحصائية 5\%.

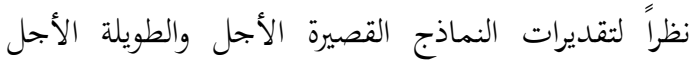

\begin{tabular}{|c|c|c|c|}
\hline $\begin{array}{c}\text { جودة التوفيق } \\
\text { Adjusted R-squared }\end{array}$ & $\begin{array}{c}\text { المعنوية الكلية للنموذج } \\
\text { Prob. (F-statistic) }\end{array}$ & $\begin{array}{l}\text { القيمة المحسوبة } \\
\text { F-statistic }\end{array}$ & النمـوذج \\
\hline 0.1662 & 0.0520 & 3.3924 & تأثير نمو الإنفاق العام على معدل البطالة \\
\hline 0.4677 & 0.0007 & 8.3224 & تأثير نمو الإنفاق العام على معدل التضخم \\
\hline 0.6068 & 0.0001 & 10.258 & تأثير نمو الإنفاق العام على معدل النمو الاقتصادي \\
\hline 0.5391 & 0.0125 & 4.0702 & تأثير نمو الإنفاق العام على التوازن الخارجي \\
\hline
\end{tabular}
وحسب الجحولين (4) و (5) يمكن تمثيل نتائج تقدير معلمات

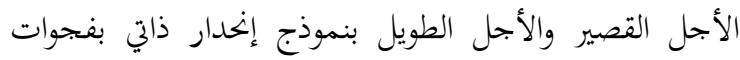

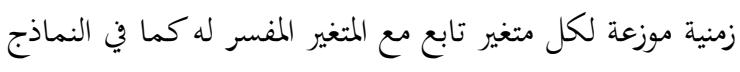

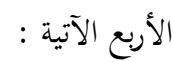

$$
\mathrm{Dy}_{1}=0.1023-0.0100 \mathrm{D}(\mathrm{x})-0.4871-0.0206 \mathrm{x}
$$

جدول (6): التقييم الإحصائي لنماذج الدراسة

المصدر : الجدول من إعداد الباحِيَن بالاعتماد على مخرجات برنامج Eviews

بينما تشير قيم الـ (Adjusted R-squared) إلى القدرة

التفسيرية النسبية لكل نموذج ، فللنموذج الأول كانت جودته ضئيلة في تفسير بياناته وهي 16.62\% أي أن متغير نمو الإنفاق العام يفسر نسبة 16.62\% من التغير الحاصل في متغير معدل التضخم ، وبعدها فأن نسبة التفسير للنموذج الثاني قد ارتفعت وبلغت 46.77\% ، أما للنموذج الثالث الذي يمتلك أعلى قدرة تفسيرية حيث بلغت نسبته 60.68\% يعني أن نمو الإنفاق العام يفسر التغيير في معدل النمو الاقتصادي بشكل جيد ، وللنموذج الأخير كانت جودة توفيقه للبيانات هي $\% 53.91$

\section{Heteroskedasticity Test}

بُغية التأكد من عدم انتهاك فرضية ثبات التباين سيتم أختبار مشكلة أختلاف التباين بالإستعانة بأختبار
لغرض فحص صلاحية نماذج الدراسة وتقييمها يتم ذلك من

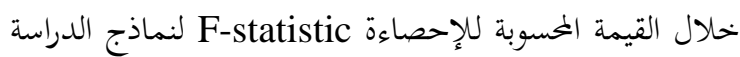

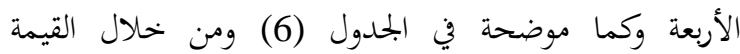

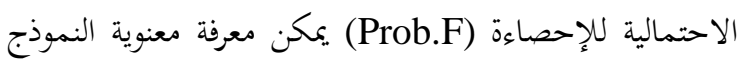

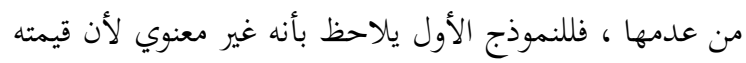
الاحتمالية هي (0.0520) وهي أكبر من مستوى الدلالة الإحصائية 5\% ، أما عند فحص المعنوية الكُلية للنماذج الثلاثة المتبقية يلاحظ أن القيم الاحتمالية لها هي ( 0.0007 ،

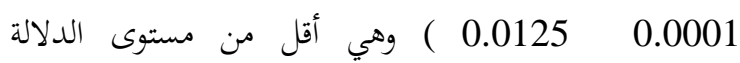
الإحصائية وهذا دليل على المعنوية الكلية لهذه

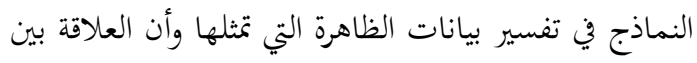
المتغيرات الثلاث المعتمد والمتغير المفسر ليست زائفة . 
Heteroskedasticity

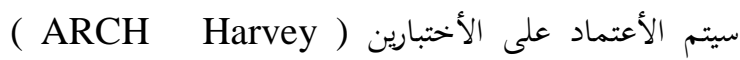
ونتائج الأختبارين كما مبينة بالجدول الآتي :

جدول (7): ملخص نتائج أختبار Heteroskedasticity

\begin{tabular}{|c|c|c|c|c|c|}
\hline \multirow{2}{*}{$\frac{1}{1}$} & \multirow{2}{*}{ نوع الأختبار } & \multicolumn{2}{|c|}{ القيمة المحسوبة للأختبار } & \multicolumn{2}{|c|}{ Prob. القيمة الأحتمالية للأختبار } \\
\hline & & F-statistic & 2.0995 & $F(2,22)$ & 0.1464 \\
\hline & & Obs ${ }^{\star}$-squared & 4.0068 & Square(2) & 0.1349 \\
\hline & $\mathrm{ARCH}$ & F-statistic & 0.1176 & $F(1,22)$ & 0.7349 \\
\hline & & $\mathrm{Obs}^{\star} \mathrm{R}$-squared & 0.1276 & Chi-Square(1) & 0.7209 \\
\hline \multirow[t]{4}{*}{2} & Harvey & F-statistic & 1.5724 & $F(3,22)$ & 0.2244 \\
\hline & & Obs ${ }^{\star}$-squared & 4.5906 & Chi-Square(3) & 0.2044 \\
\hline & $\mathrm{ARCH}$ & F-statistic & 1.3107 & $F(1,23)$ & 0.2640 \\
\hline & & $\mathrm{Obs}^{*} \mathrm{R}$-squared & 1.3479 & Chi-Square(1) & 0.2457 \\
\hline \multirow[t]{4}{*}{3} & Harvey & F-statistic & 0.7451 & $F(4,20)$ & 0.5726 \\
\hline & & $\mathrm{Obs}^{*} \mathrm{R}$-squared & 3.2425 & Chi-Square(4) & 0.5181 \\
\hline & $\mathrm{ARCH}$ & F-statistic & 4.1457 & $F(1,22)$ & 0.0540 \\
\hline & & Obs $^{*}$-squared & 3.8055 & Chi-Square(1) & 0.0511 \\
\hline \multirow[t]{4}{*}{4} & Harvey & F-statistic & 0.4480 & $F(8,13)$ & 0.8710 \\
\hline & & $\mathrm{Obs}^{*} \mathrm{R}$-squared & 4.7549 & Chi-Square(8) & 0.7834 \\
\hline & $\mathrm{ARCH}$ & F-statistic & 0.0764 & $F(1,19)$ & 0.7852 \\
\hline & & Obs*R-squared & 0.0841 & Chi-Square(1) & 0.7718 \\
\hline
\end{tabular}

المصدر : الجدول من إعداد الباحثَين بالاعتماد على مخرجات برنامج Eviews

تشير نتائج أختبار أختلاف التباين في الجحدول (7) بأن 8. 8. أختبار الأرتباط الذاتي للبواقي : تم الأعتماد على أختبار

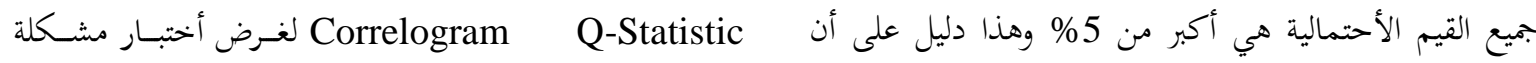

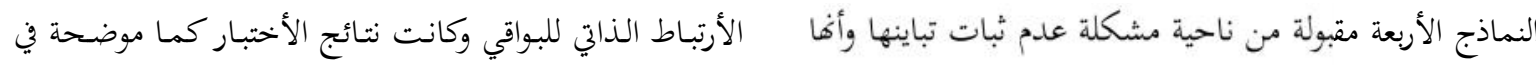

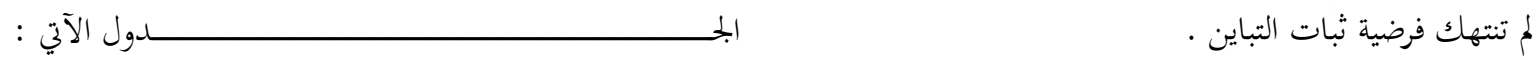

جدول (8): ملخص نتائج أختبار Correlogram Q-Statistic

\begin{tabular}{cccccc}
\hline Prob. & Q-Statistic & PAC & AC & Lag & النموذn \\
\hline 0.459 & 0.5486 & -0.140 & -0.140 & 1 \\
\hline 0.650 & 0.8607 & -0.125 & -0.103 & 2 \\
\hline 0.479 & 2.4798 & 0.203 & 0.230 & 3 \\
\hline
\end{tabular}


بحلة جامعة دهوك، البخلا: 22، العدد: 1 (العلوم الانسانية والاجتماعية)، ص 335-357 2019

https://doi.org/10.26682/hjuod.2019.22.1.18

\begin{tabular}{lllll}
\hline \hline 0.641 & 2.5185 & 0.015 & -0.035 & 4 \\
\hline 0.833 & 0.0443 & 0.039 & 0.039 & 1 \\
\hline 0.880 & 0.2563 & -0.085 & -0.084 & 2 \\
\hline 0.968 & 0.2564 & 0.006 & -0.001 & 3 \\
\hline 0.442 & 3.7397 & -0.335 & -0.324 & 4 \\
\hline 0.669 & 0.1831 & -0.081 & -0.081 & 1 \\
\hline 0.673 & 0.7924 & -0.152 & -0.144 & 2 \\
\hline 0.847 & 0.8092 & -0.002 & 0.023 & 3 \\
\hline 0.286 & 5.0129 & -0.393 & -0.362 & 4 \\
\hline 0.857 & 0.0324 & 0.036 & 0.036 & 1 \\
\hline 0.877 & 0.2618 & 0.092 & 0.093 & 2 \\
\hline 0.951 & 0.3458 & -0.062 & -0.055 & 3 \\
\hline 0.982 & 0.4064 & 0.042 & 0.045 & 4 \\
\hline
\end{tabular}

المصدر : الجدول من إعداد الباحَيَّن بالاعتماد على خرجات برنامج Eviews

3- كان الأداء الاقتصادي للحكومة السعودية جيداً من خلال

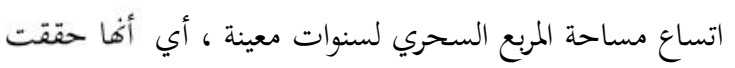

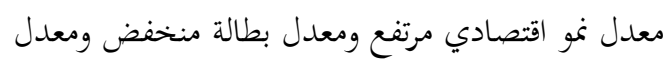
تضخم منخفض مع ارتفاع نسبة رصيد ميزان المدفوعات إلى مئل

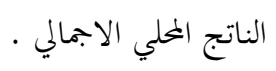

4- لم تستطع السياسة الانفاقية في المملكة العربية السعودية تحقيق كافة أهداف السياسة الاقتصادية في بعض السنوات ، وهذا ما أظهره الضيق في مساحة المربع السحري لمتغيرات معينة

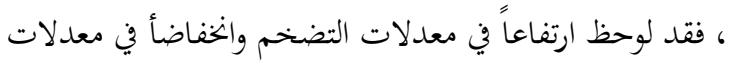

$$
\text { النمو الاقتصادي لسنوات معينة. }
$$

5- اتسمت معدلات البطالة في المملكة العربية السعودية

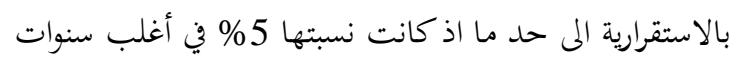

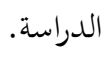

6-اتسم رصيد ميزان المدفوعات في المملكة العربية السعودية بالتحسن الى حد كبير نتيجة لارتفاع أسعار النفط وارتفاع قيمة الصادرات الذي بدأ منذ سنة 2000 ، وقد بدأ هذا لـأ

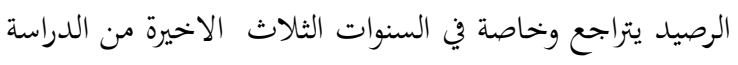
بسبب النخفاض أسعار النفط وبالتالي انخفاض قيمة الصادرات
يشير الجحدول (8) إلى قيم دالة الأرتباط الذاتي AC وقيم

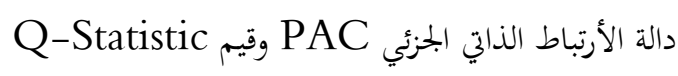

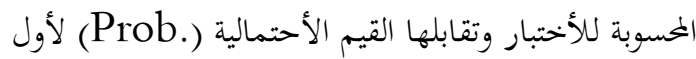
أربع تخلفات زمنية فقط ، يمكن ملاحظة أن جميع القيم الأحتمالية (Prob) هي أكبر من مستوى الدلالة الإحصائية

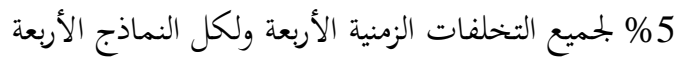

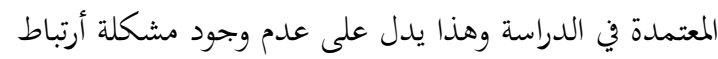

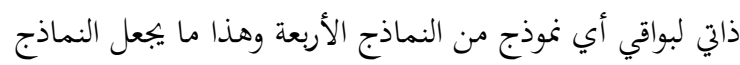

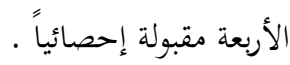

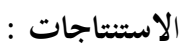
توصلت الدراسة للاستنتاجات الآتية :

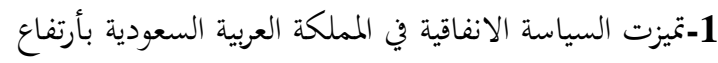

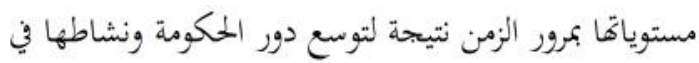
التأثير على الحياة الاقتصادية والاجتماعية . 2-تسعى الحكومة السعودية من خلال سياستها الانفاقية التدخل في النشاط الاقتصادي والاجتماعي لتحقيق التوازن الاقتصادي والاجتماعي. 
المعروض النقدي وبما يخدم أهداف السياسة الاقتصادية

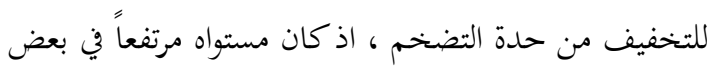

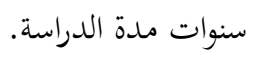

3- تنويع مصادر الايرادات وتوجيه الفوائض المالية نحو المشاريع

الانتاجية من اجل الاستفادة من الايدي العاملة المحلية لتخفيض

$$
\text { معدلات البطالة وتحقيق النمو الاقتصادي في السعودية . ل }
$$

4-دعم المؤسسات الصغيرة والمتوسطة وتقديم الاعانات

للمستثمرين المحليين وتخفيف الضرائب عنهم وتشجيعهم على موسئ

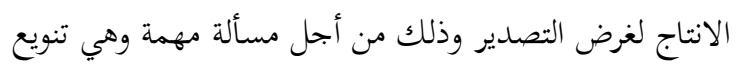
الصادرات وعدم الاعتماد الكلي على صادرات النفط لتحقيق التوازن المستمر في ميزان المدفوعات . 5ـ المحافظة على معدلات النمو الاقتصادي المرتفعة في المستقبل

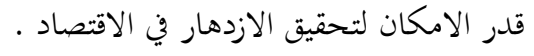

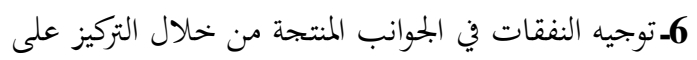
الانفاق الاستثماري وذلك من أجل تخفيض معدلات البطالة

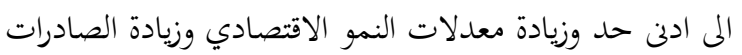

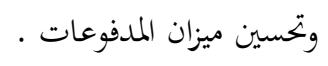

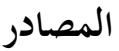
المصادر العربية

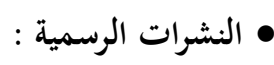

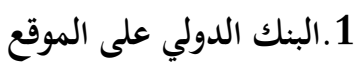
http://data.albankaldawli.org

\section{الرسائل والاطاريح الجامعية : الرئ}

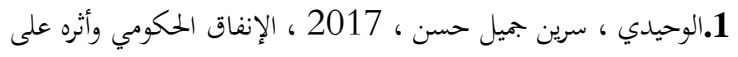

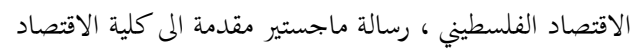

$$
\text { والعلوم الإدارية ، جامعة الأزهر -غزة . }
$$

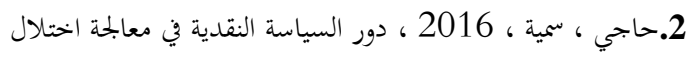

ميزان المدفوعات ، رسالة ماجستير مقدمة الى كلية العلوم

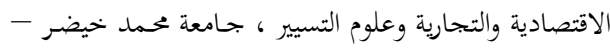

$$
\text { بسكرة. }
$$

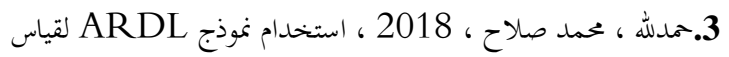

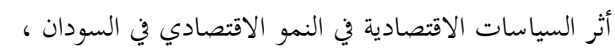

مقارنة بارتفاع فاتورة الواردات لتلبية المستوى المرتفع للطلب المحلي من السلع والخدمات العامة .

7-تبين من نتائج اختبار جذر الوحدة تبين بان المتغيرات (نمو الإنفاق العام ، معدل التضخم ، معدل النمو الاقتصادي) كانت مستقرة عند المستوى بينما المتغيرين معدل البطالة والتوازن الخارجي كانت مستقرة عند الفرق الاول. 8-من خلال نتائج اختبار Bounds للتكامل المشترك تبين بأن هناك علاقة توازنية طويلة الاجل بين الإنفاق العام وكلا من

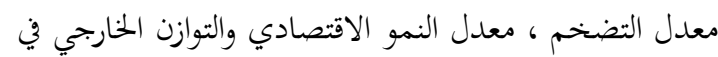
حين لم يكن هناك علاقة توازنية طويلة الاجل بين الإنفاق العام ومعدل البطالة.

9-تبين من خلال نتائج علاقة الاثر في الاجل القصير بان

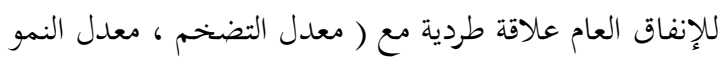

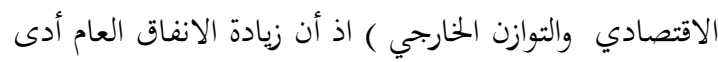

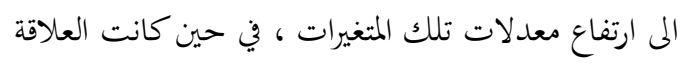

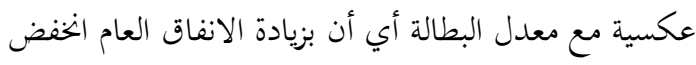
معدل البطالة ؛ أما في الاجل الطويل فقد كان للإنفاق العام

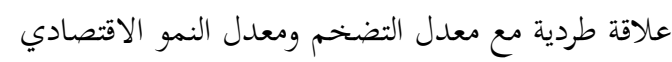
وعلاقة عكسية مع معدل البطالة والتوازن الخارجي . 10-تبين من خلال المعنوية الاحصائية لقيمة (T) أن للإنفاق

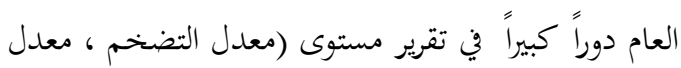
النمو الاقتصادي والتوازن الخارجي) في الاجل القصير ، وفي

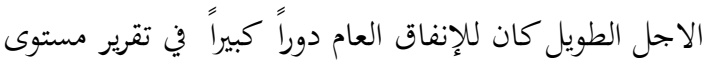
معدل التضخم ومعدل النمو الاقتصادي. التوصيات: يوصي الباحثين بالآتي :

1ـعدم الاعتماد بشكل كبير على ايرادات النفط في تمويل

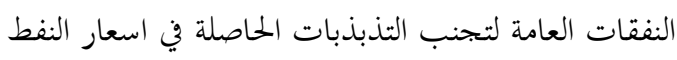
والاعتماد على ادوات تمويلية جديدة تتسم بالاستقرار الى حد . L

2-على الحكومة السعودية استخدام ادوات السياسة المالية

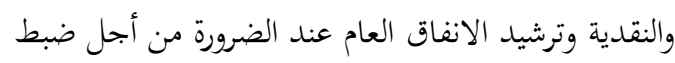


تودارو ، ميشيل ، 2006 ، التنمية الاقتصادية ، دار المريخ

$$
\begin{aligned}
& \text { للنشر ، الرياض ، السعودية . } \\
& \text { أ. المصادر الاجنبية : }
\end{aligned}
$$

Articles :

1. Furuoka , Fumitaka \& Munir, Qaiser, 2014, Unemployment and Inflation in Malaysia: Evidence from Error Correction Model, Malaysian Journal of Business and Economics, Vol. 1 , No. 1.

2. habil. Gheorghe SĂVOIU, Emilia GOGU \& Marian TAICU , 2017 , Hierarchies of Asociative Dynamics, Starting From Romania's Macro-Economic Imbalances in the EU-28. , The Journal Of National Institute Of Statistics, Vol. 65, Iss. 3.

3. Jajere , Hauwa Buba , 2016 , Impact of Unemployment on Economic Growth in Nigeria 1980 - 2010 , Journal of Business and Finance Management Research, Vol.2, No.10 .

4. Manyeki , John Kibara \& Kotosz, Balazs , 2017, Empirical Analysis of the Wagner Hypothesis of Government Expenditure Growth in Kenya: ARDL Modelling Approach, Journal of Economic Literature (JEL), Vol.13, No. 2 , pp. 45-57 .

5. Nehme, Georges , 2014 , Ensuring Effectiveness of Economic and Monetary Policies through Considering Economic Schools of Thought: Lebanon 1990-2010, Open Journal of Social Sciences, Vol. 2.

6. Neantro , Saavedra-Rivanoa \& Joanilio Rodolpho Teixeiraba , 2017 , Magic hypercube and index of welfare and sustainability, Economia, Vol. 18.

7. Nkoro, Emeka \& Uko , Aham Kelvin , 2016 , Autoregressive Distributed Lag (ARDL) cointegration technique : application and interpretation, Journal of Statistical and Econometric Methods, vol.5 , no.4, 63-91 .

8. Razak, Mohamad Idham Md - Asliza Mohd Yusof- Wan Nor Syazana- Wan Effa JaafarAdi Hakim Talib , 2014 , Factors Influencing Unemployment among Graduates in Malaysia, Journal of Economics and Sustainable Development, Vol.5, No.11 .

- Books :

1. Delong, J.Bradford, 2002 , Macroeconomics, Mc Graw-Hill Companies, Inc. , New York ,USA.

2. Samuelson, Paul A.\& Nordhaus, William D., 2001, Economics International, McGraw Hill, New York .

Shapiro, Edward , 1995 , Macroeconomic Analysis, Thomson Learning .

$$
\begin{aligned}
& \text { رسالة ماجستير مقدمة الى كلية الدراسات العليا ، جامعة }
\end{aligned}
$$

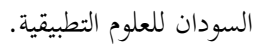

$$
\begin{aligned}
& \text { 4.دشوشة ، أية - بن زاوي ، خديجة ، } 2017 \text { ، أثر ترشيد الإنفاق العام السية. }
\end{aligned}
$$

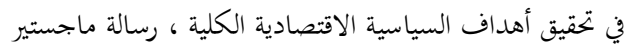

$$
\begin{aligned}
& \text { مقدمة الى كلية العلوم الاقتصادية والتجارية وعلوم التسيير ، } \\
& \text { جامعة محمد بوضياف بالمسيلة . } \\
& \text { 5.سفاحلو ، حميدة - زناد ، أمينة ، } 2017 \text { ، دورياف المسلة السياسة النقدية في } \\
& \text { تحقيق أهداف مربع Kaldor ، رسالة ماجستير مقدمة الى كلية } \\
& \text { العلوم الاقتصادية والتجارية وعلوم التسيير،جامعة الجيلالي بونعامة }
\end{aligned}
$$

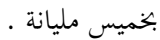

$$
\begin{aligned}
& \text { 6.بحفوظ ، فاطمة ، } 2015 \text { ، أثر السياسة المالية على سلوك بعض }
\end{aligned}
$$

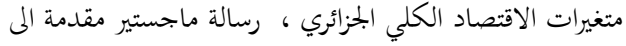

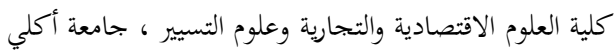

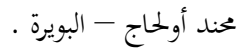

$$
\begin{aligned}
& \text { 7.مقراني ، حميد ، } 2016 \text { ، أثر الإنفاق الحكومي على معدلي البطالة و البحاج } \\
& \text { التضخم في الجزائر ، رسالة ماجستير مقدمة الى كلية العلوم التهاف } \\
& \text { الاقتصادية والتجارية وعلوم التسيير ، جامعة أعمد بوقرة - }
\end{aligned}
$$

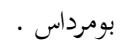

$$
\begin{aligned}
& \text { 8 8نعماني ، سومية - عبرون ، غنية ، } 2016 \text { ، دور السياسة الاقتصادية } \\
& \text { الكلية في تحقيق التوازن في ميزان المدفوعات ، رسالة ماجستير } \\
& \text { مقدمة الم كلية العلوم الاقتصادية والتجارية وعلوم التسيير ، }
\end{aligned}
$$

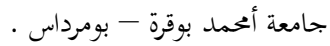

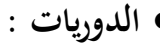

$$
\begin{aligned}
& \text { 1 الأعظمي ، حميد فرج ، (2000) ، الأثار الاقتصادية لرسالة الثدبير }
\end{aligned}
$$

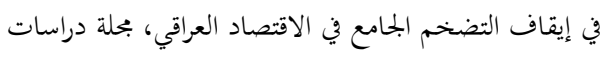

$$
\begin{aligned}
& \text { اقتصادية، العدد (2) . }
\end{aligned}
$$

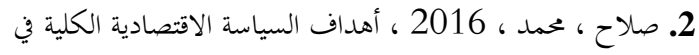

$$
\begin{aligned}
& \text { الجزائر حسب المربع السحري لكالدور ، بحلة كلية العلوم } \\
& \text { الاقتصادية والتسيير والعلوم التجارية ، العدد } 16 .
\end{aligned}
$$

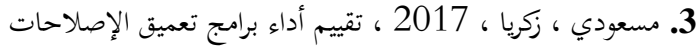

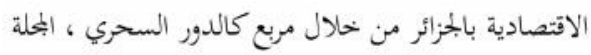

$$
\begin{aligned}
& \text { الجزائرية للتنمية الاقتصادية ، العدد } 6 \text {. }
\end{aligned}
$$

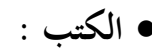

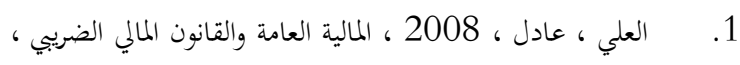

$$
\begin{aligned}
& \text { دار إثراء للنشر والتوزيع ، عمان ، الاردن . }
\end{aligned}
$$

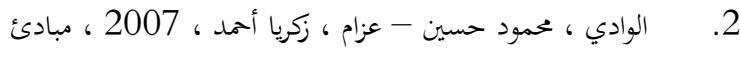

$$
\begin{aligned}
& \text { المالية العامة ، دار المسيرة للنشر والتوزيع ، عمان ، الاردن . }
\end{aligned}
$$


ئا رمانجا قه كولينى ئه وه قياسا كارتيَكرنا خه رجين گشتى ل سه ر گورانكاريَن (المربع السحرى) ل (kaldor)

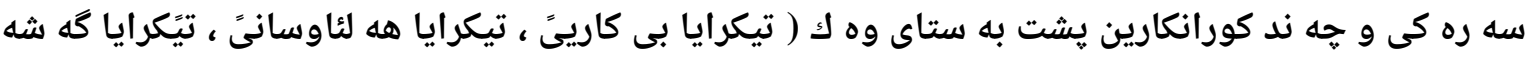

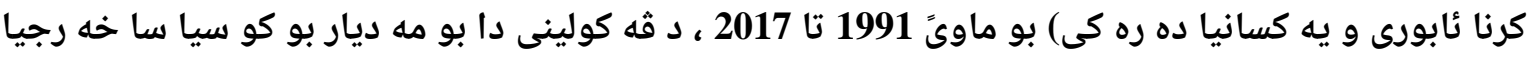

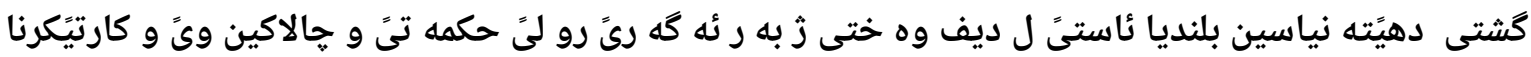

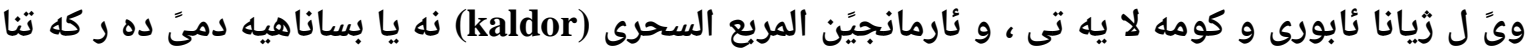
باشيى ل هنده ك لا يه نين (المربع السحرى) به رامبه ر فئ جه ندى بومه ديار بو كيم بون و خرابى ل هنده لك لا

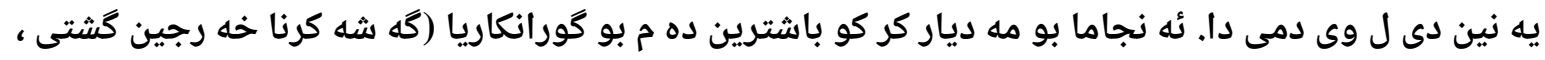

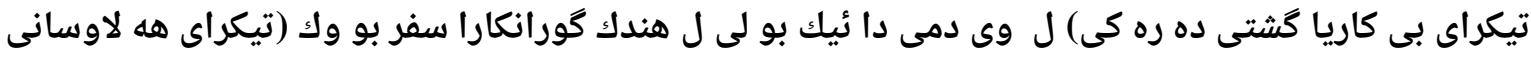
و تيكرلى گه شه كرنا ثابورى) د خلاليً ئه نجامىً تيستا جزر الواحده ديار بو كو گورانكارين (كه شه كرنا خه

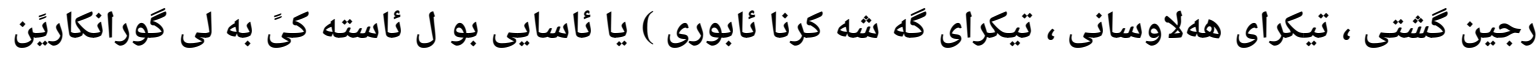

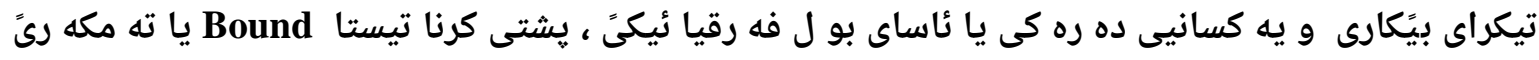

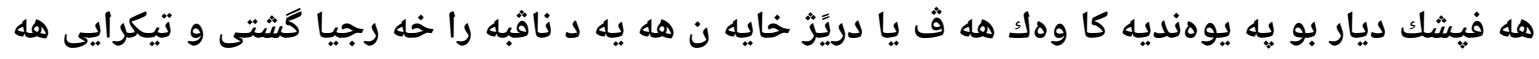

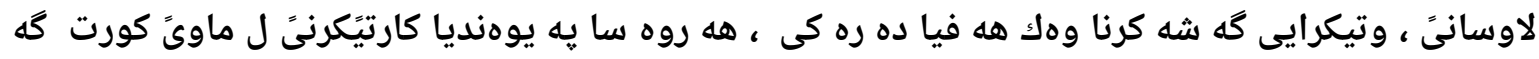

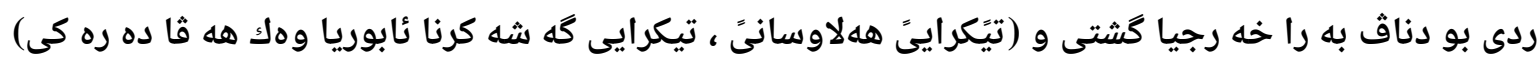

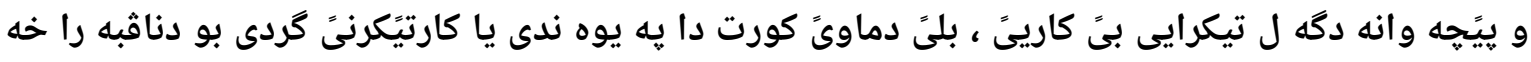

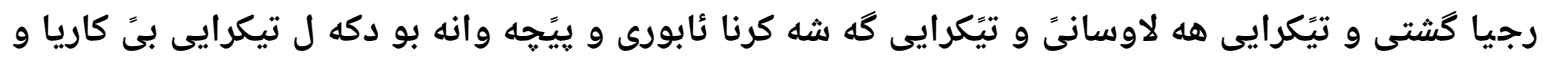

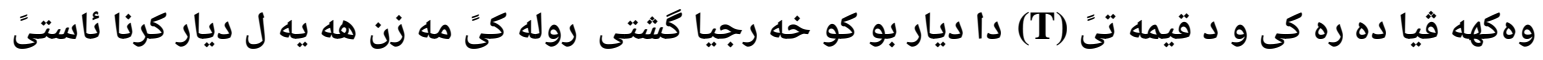

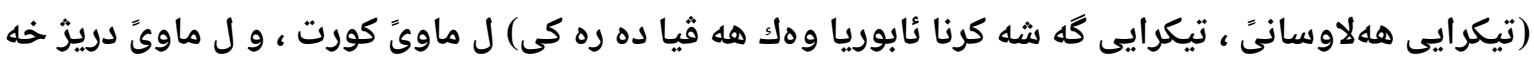

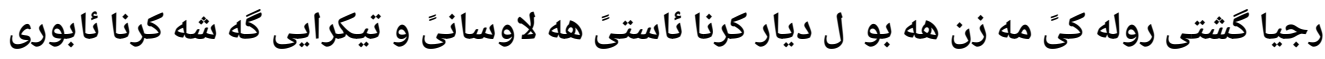




\title{
MEASUREMENT AND ANALYSIS THE IMPACT OF PUBLIC EXPENDITURE ON THE KALDOR'S MAGIC SQUARE VARIABLES IN SAUDI ARABIA USING THE STATISTICAL TECHNIQUE OF AUTO-REGRESSIVE DISTRIBUTED LAG MODEL (ARDL) FOR THE PERIOD 1991-2017
}

\author{
IBRAHEEM MOHAMMEd HuSSAIN AND SUNDUS BAHJAT JAMEEL \\ College of Administration and Economics, University of Duhok, Kurdistan Region-Iraq
}

\begin{abstract}
The study aims to measuring and analyzing the effect of public expenditure on the variables of kaldor's magic square in the Kingdom of Saudi Arabia based on the annual data of public expenditure as an independent variable and the number of dependent variables represented by (unemployment rate, inflation rate, economic growth rate and external balance) for a time series extending from 1991 to 2017 , It was found during the study that the spending policy was characterized by high levels over time as a result of the expansion of the role of the government and its activities to effect on the economic and social life, and achieving the goals of the kaldor's magic square is not easy when there was improvement in some axes of the magic square, per contra there was a deterioration in other axes in the same year, The results revealed that the best period of delay for the variables (growth of public spending, unemployment rate and external balance) was one slowdown while zero for variables (inflation rate and economic growth rate) The results of the unit root test showed that the variables (growth of public expenditure, inflation rate, economic growth rate) were stable at the level, while the variables unemployment rate and external balance were stable at the first difference. After the Bounds test of co-integration, it was found that there is a long-term balance relationship between public spending and inflation, economic growth rate and external balance ; in addition, the short-term effect relationship was positive between public expenditure with (inflation rate, economic growth rate and external balance) and reverse with the unemployment rate; In the long term, the relationship of influence was positive between public expenditure and both the inflation and economic growth rate and inverse with both the unemployment rate and external balance; And through the statistical significance of the value the value $(T)$ shows that public expenditure plays a large role in determining the level of inflation, economic growth rate and external balance. In the short term ; In the long term, public expenditure has played a large role in determining the rate of inflation and the rate of economic growth.
\end{abstract}

